\title{
A New Multiscale Model for the Madden-Julian Oscillation
}

\author{
Joseph A. Biello And Andrew J. Majda \\ Courant Institute of Mathematical Sciences, Center for Atmosphere-Ocean Science, New York University, New York, New York
}

(Manuscript received 30 July 2004, in final form 8 November 2004)

\begin{abstract}
A multiscale model of the MJO is developed here that accounts, in a simplified fashion, for both the upscale transfer from synoptic to planetary scales of momentum and temperature from wave trains of thermally driven equatorial synoptic-scale circulations in a moving convective envelope as well as direct mean heating on planetary scales. This model involves idealized thermally driven congestus synoptic-scale fluctuations in the eastern part of the moving wave envelope and convective superclusters in the western part of the envelope. The model self-consistently reproduces qualitatively many of the detailed structural features of the planetary circulation in the observations of the MJO, including the vertical structure in both the westerly onset region and the strong westerly wind burst region, as well as the horizontal quadrupole planetary vortex structure. The westerly midlevel inflow in the strong westerly region and the quadrupole vortex are largely produced in the model by the upscale transport of momentum to the planetary scales, while the midlevel easterly jet in the westerly onset region is substantially strengthened by this process. The role of wave trains of tilted organized synoptic-scale circulations is crucial for this fidelity with observations. The appeal of the multiscale models developed below is their firm mathematical underpinnings, simplicity, and analytic tractability while remaining self-consistent with many of the features of the observational record.
\end{abstract}

\section{Introduction}

Convection in the Tropics has a profound impact on short-term climate. Observational data indicate that tropical deep convection is organized on a hierarchy of scales ranging from cumulus clouds over a few kilometers to intraseasonal oscillations over planetary scales of order $40000 \mathrm{~km}$ (Nakazawa 1988; Hendon and Liebmann 1994; Wheeler and Kiladis 1999). The mechanisms for this behavior present a major unsolved problem, despite the fact that there has been extensive research over the last few decades on these topics through parameterization of convection in general circulation models (Emanuel and Raymond 1993), as well as theory (Majda and Shefter 2001; Majda et al. 2004, and references therein).

The dominant component of intraseasonal variability in the Tropics is the 40-to-50-day tropical intraseasonal oscillation, often called the Madden-Julian oscillation (MJO) after its discoverers (Madden and Julian 1972). In the troposphere, the MJO is an equatorial planetaryscale wave envelope of complex multiscale convective processes which propagates across the Indian Ocean

Corresponding author address: Joseph A. Biello, Courant Institute of Mathematical Sciences, 251 Mercer Street, New York, NY 10012.

E-mail: biello@cims.nyu.edu and western Pacific at a speed of roughly $5 \mathrm{~m} \mathrm{~s}^{-1}$ (Nakazawa 1988; Hendon and Salby 1994; Hendon and Liebmann 1994; Maloney and Hartmann 1998). The planetary-scale circulation anomalies associated with the MJO significantly affect monsoon development, intraseasonal predictability in midlatitudes, and impact the development of the El Niño-Southern Oscillation (ENSO) in the Pacific Ocean (Madden and Julian 1994; Vecchi and Harrison 2000; Zhang and Anderson 2003). Present-day computer general circulation models (GCM) typically poorly represent the MJO (Sperber et al. 1997). One conjecture for the reason for this poor performance of GCMs is the inadequate treatment across multiple spatial scales of the interaction of the hierarchy of organized structures that generate the $\mathrm{MJO}$ as their envelope.

There have been a large number of theories attempting to explain the MJO through a specific linearized mechanism, such as evaporation wind feedback (Emanuel 1987; Neelin et al. 1987), boundary layer frictional convective instability (Wang and Rui 1990), stochastic linearized convection (Salby et al. 1994), radiation instability (Raymond 2001), and the planetary-scale linear response to moving heat sources (Chao 1987). Moncrieff (2004) has recently developed an interesting phenomenological nonlinear theory for the upscale transport of momentum from equatorial mesoscales $[O(300 \mathrm{~km})]$ to planetary scales and has applied this 
theory to explain the "MJO-like" structure in recent "super parameterization" computer simulations (Grabowski 2001) with a scale gap (no resolution at all) on scales between 200 and $1200 \mathrm{~km}$. Despite all of these interesting contributions, the problem of explaining the MJO has recently been called the search for the "holy grail" of tropical atmospheric dynamics (Raymond 2001).

Basic understanding of the structure of the MJO has been gained through observations. Statistical composites of reanalysis data (Hendon and Salby 1994; Kiladis et al. 2005) give insight into the horizontal and vertical structure of the planetary-scale MJO envelope with crucial features documented such as quadrupole vortices in the horizontal flow field (Hendon and Salby 1994, Fig. 3). The detailed analysis of observations of two individual MJO events that passed over the intensive flux array during the TOGA COARE field campaign has given significant new insight into features such as the heating rates and detailed vertical structure in the wave (Lin and Johnson 1996; Johnson and Lin 1997; Yanai et al. 2000; Houze et al. 2000).

The simplest theoretical model for the MJO is given as the planetary-scale response of a moving heat source with velocity prescribed at the MJO speed through the linear shallow water equations for a first baroclinic mode (Matsuno 1966; Gill 1980; Chao 1987); Houze et al. (2000) call this the Kelvin-Rossby wave paradigm and use it as a rough guideline for understanding observations even though the vertical structure of the model is very different and often at odds with the actual observations (Houze et al. 2000).

In a recent study, the present authors (Majda and Biello 2004) have proposed a new way to look at the $\mathrm{MJO}$ as a multiscale process in space on intraseasonal time scales. In that work, a multiscale model was developed that clearly demonstrates the fashion in which planetary-scale circulations sharing several features in common with the MJO are generated on intraseasonal time scales through the upscale transfer of kinetic and thermal energy generated by wave trains of organized synoptic-scale circulations having features in common with observed convective superclusters. The theoretical framework utilized there and in the present study is the intraseasonal planetary equatorial synoptic dynamics (IPESD) model derived recently (Majda and Klein 2003). The IPESD model is a multiscale balanced model, systematically derived from the primitive equations through asymptotic mathematical procedures and provides simplified equations for the upscale transfer of energy from a wave train of equatorial synoptic-scale circulations to the planetary-scale as well as the response on planetary scales to the large scale envelope of heating. As shown recently (Majda and Klein 2003; Majda and Biello 2004), the IPESD models have firm mathematical underpinnings, conceptual simplicity, and analytic tractability while representing some of the cru- cial multiscale interactions for the planetary-scale response. The IPESD models are also the theoretical basis for the present study.

The goal of the present paper is to develop a simplified model of the MJO that is self-consistent, at least qualitatively, with the observational record. Observations suggest that this synoptic-scale organization within the MJO is manifested as westward-tilted convective supercluster systems (Fig. 1 in Moncrieff and Klinker 1997) in the Rossby-gyre region of the MJO, while it is more akin to lower troposphere congestus heating in the eastern region leading the "westerly onset" in the MJO (Johnson and Lin 1997; Houze et al. 2000; Kiladis et al. 2005). The idea advanced in this paper is that the planetary-scale flow associated with the MJO can be explained by a combination of mean planetary-scale and fluctuating synoptic-scale heating within an eastward-moving convective envelope. In this moving convective envelope model, the synoptic-scale fluctuations take the form of westward-tilted convective superclusters in the west of the convective envelope and lower troposphere congestus heating in the east of the convective envelope with a conceptually self-consistent similar profile for the mean heating. A central issue addressed here is how much of the planetary circulation in the MJO is created by mean planetary-scale heating with an appropriate structure versus the circulation induced by eddy flux convergences from synoptic-scale wave trains in the moving convective envelope.

The IPESD models are summarized in section 2. The moving convective envelope models are developed in detail in section 3. Section 4 describes the planetary circulations that emerge from the upscale transfer of energy from equatorial synoptic-scale wave trains with an eastern congestus and western supercluster planetary-scale wave envelope, while section 5 contains the effects on planetary scales of mean heating with a similar structure. The MJO model is presented in section 6 by utilizing the previous results from sections 4 and 5 and this model is compared with the detailed horizontal and vertical structure of observations. The paper ends with a discussion. These results are presented in a didactic fashion. The reader who prefers a more direct route to the main results in the MJO model can consult the short summary in Table 1 for the structure of the paper. In particular, as shown there, for the equatorial symmetric MJO model the reader only needs Eqs. (2.4)-(2.7), (3.3)-(3.7), Figs. 1, 2, 15, 16, and the discussion in section 6 to understand these final results.

\section{The IPESD model for simplified intraseasonal dynamics}

The fundamental model for the dynamical behavior of the troposphere assumed here is the constant buoyancy frequency Boussinesq equations with standard 
TABLE 1. MJO model summary.

\begin{tabular}{|c|c|}
\hline \multicolumn{2}{|l|}{ Preliminary } \\
\hline IPESD model & Eqs. (2.4)-(2.7) \\
\hline Convective wave trains & Eqs. (3.3)-(3.7) \\
\hline Flux convergence (equatorial) & Figs. 1 and 2 \\
\hline Flux convergence (off-equatorial) & Figs. 3 and 4 \\
\hline \multicolumn{2}{|c|}{ Planetary equatorial symmetric $\mathrm{MJO}$} \\
\hline Congestus/supercluster MJO model & Figs. 15 and 16 \\
\hline $\begin{array}{l}\text { Effect of upscale fluxes alone } \\
\text { (C/SC) }\end{array}$ & $\begin{array}{l}\text { Figs. } 7 \text { and } 8, \\
\text { Eq. }(4.2)\end{array}$ \\
\hline $\begin{array}{l}\text { Effect of mean heating alone } \\
(\mathrm{C} / \mathrm{SCMH})\end{array}$ & $\begin{array}{l}\text { Figs. } 13 \text { and } 14, \\
\text { Eqs. (5.3), (5.4) }\end{array}$ \\
\hline \multicolumn{2}{|c|}{ Planetary off-equatorial MJO } \\
\hline Congestus/supercluster MJO model & Figs. 17 and 18 \\
\hline Effect of upscale fluxes alone (C/SC) & Figs. 9 and 10 \\
\hline
\end{tabular}

troposphere value for the buoyancy frequency, $N=$ $10^{-2} \mathrm{~s}^{-1}$ and a tropospheric height of roughly $16 \mathrm{~km}$ (Majda 2003). Rigid lid boundary conditions with no vertical flow are assumed at the bottom of the free troposphere at $0 \mathrm{~km}$ above the surface and at the top of the troposphere at $16 \mathrm{~km}$. This is a simplified version of the primitive equations for the lower middle troposphere where both coupling to the boundary layer and also to the stratosphere are ignored. A recent study of two-day waves (Haertel and Kiladis 2004) shows, in that context, that the rigid lid approximation is an excellent one for capturing lower middle troposphere dynamics. For these reasons, complete fidelity of the model developed below is only anticipated in the lower middle troposphere. Under these circumstances, the natural reference speed, $c_{\text {ref }}$, is the gravity wave speed of the first baroclinic vertical mode, $c=50 \mathrm{~m} \mathrm{~s}^{-1}$ and the standard equatorial synoptic length and time scales, $L_{s}, T_{s}$, are defined by $L_{s}=(c / \beta)^{1 / 2}=1500 \mathrm{~km}$ and $T_{s}=$ $(c \beta)^{-1 / 2}=8.3 \mathrm{~h}$ where $\beta$ represents the leading order curvature effect of the earth at the equator (Majda 2003). Below $(U, V, W)$ denote the $x, y, z$ (zonal, meridional, and vertical) components of velocity, respectively, whereas the $(x, y, z)$ coordinates are identified with the east-west or zonal, north-south or meridional, and vertical directions, respectively. The remaining dynamic variables are the pressure, $P$, and equivalent temperature, $\theta$. Since the reference flow speed, $c=50$ $\mathrm{m} \mathrm{s}^{-1}$, is very large, it is natural to consider flows for the equatorial primitive equations where the Froude number, defined by the ratio of typical horizontal velocity magnitudes and the basic wave speed, $\mathrm{Fr}=v_{\text {ref }} / c=\epsilon$, is a small parameter since values of $\epsilon$ in the range $0.1 \leq \epsilon$ $\leq 0.4$ give very reasonable flow velocities for the tropical troposphere.

Intuitively, one regime of balanced dynamics occurs on the equatorial synoptic length scale, $L_{s}$, but on the larger advective time scale $T_{I}=L_{s} / v_{\mathrm{ref}}$, which is about 3.5 days; since ten units of this time scale span more than one month, $T_{I}$ is an intraseasonal time scale. Since the equatorial circumference is $40000 \mathrm{~km}$ and the equatorial synoptic-scale, $L_{s} \approx 1500 \mathrm{~km}$, it is very natural to have envelope modulations of equatorial synoptic-scale behavior on the planetary-scale, $X=\epsilon x$. The simplified multiscale equations derived from the primitive equations under the above assumptions through systematic asymptotic principles are the IPESD equations [Majda and Klein (2003), see pages 395-396, 398, 405 for details]. The IPESD models readily allow for zonal flow velocities of order $10 \mathrm{~m} \mathrm{~s}^{-1}$ and heating sources, $S^{\theta}$, with magnitude of $10 \mathrm{~K} \mathrm{day}^{-1}$ (Majda and Klein 2003), reasonable for equatorial synoptic-scale dynamics and their corresponding convective forcings. These are the values that emerge from the conservative choice $\epsilon=$ 0.125 , which is utilized below to interpret the IPESD solutions. The scales associated with all of the variables of the IPESD equations are summarized in Table 2.

Since the IPESD equations separate the variables of the flow into zonal synoptic-scale means (which vary only on planetary scales) and fluctuations on the synoptic-scale, it is convenient to define the zonal synoptic average. An atmospheric variable, $g(X, x, y, z, t)$, varies both on zonal synoptic and planetary scales and therefore can be split into its synoptic-scale mean and fluctuations such that

$$
g(X, x, y, z, t)=\bar{g}(X, y, z, t)+g^{\prime}(X, x, y, z, t),
$$

where

$$
\bar{g}(X, y, z, t)=\lim _{L \rightarrow \infty} \frac{1}{2 L} \int_{-L}^{L} g(X, x, y, z, t) d x .
$$

In standard notation from turbulence theory, $\bar{g}(X, y, z, t)$ denotes the large scale mean variables that do not involve fluctuations on the $x$ scale directly while

TABLE 2. The scales and nondimensional parameters of the IPESD model. Brackets indicate that the value of one unit of the nondimensional variable corresponds to given scale.

\begin{tabular}{lll}
\hline \hline \multicolumn{1}{c}{ Physical quantity } & \multicolumn{1}{c}{ Name } & \multicolumn{1}{c}{ Value or unit scale } \\
\hline Froude number & $\epsilon$ & 0.125 \\
Gravity wave speed & $c$ & $50 \mathrm{~m} \mathrm{~s}^{-1}$ \\
Equatorial time scale & $T_{E}$ & $(c \beta)^{-1 / 2}=8.3 \mathrm{~h}$ \\
Equatorial deformation & $L_{s}$ & $(c / \beta)^{1 / 2}=1500 \mathrm{~km}$ \\
$\quad$ radius & & \\
Troposphere height & $H_{T}$ & $16 \mathrm{~km}$ \\
Synoptic-scale dimensions & {$[x, y]$} & $L_{s}=1500 \mathrm{~km}$ \\
Vertical dimension & {$[z]$} & $H_{T} / \pi \approx 5 \mathrm{~km}$ \\
Zonal planetary scale & {$[X]$} & $L_{s} / \epsilon=12000 \mathrm{~km}$ \\
Planetary advection time & {$[t]$} & $T_{I} \equiv T_{E} / \epsilon \approx 3 \mathrm{days}$ \\
Horizontal velocity scale & {$\left[u^{\prime}, v^{\prime}, \bar{U}\right]$} & $\epsilon c=6.25 \mathrm{~m} \mathrm{~s}^{-1}$ \\
Vertical velocity scale & {$\left[w^{\prime}\right]$} & $\epsilon c H / L_{s}=2.5 \mathrm{~cm} \mathrm{~s}$ \\
Temperature scale & {$\left[\theta^{\prime}, \bar{\Theta}\right]$} & $3 \mathrm{~K}$ \\
Pressure scale & {$\left[p^{\prime}, \bar{P}\right]$} & $\epsilon c^{2}=312\left(\mathrm{~m} \mathrm{~s}^{-1}\right)^{2}$ \\
Synoptic-scale heating rate & {$\left[S^{\theta^{\prime}}\right]$} & $10 \mathrm{~K}$ day \\
Planetary-scale heating rate & {$\left[S^{\theta}\right]$} & $1.25 \mathrm{~K}$ day ${ }^{-1}$ \\
Momentum drag rate & $d$ & $T_{I}(5 \text { days })^{-1} \approx 0.55$ \\
Thermal dissipation rate & $d_{\theta}$ & $T_{I}\left(15\right.$ days $^{-1} \approx 0.18$ \\
\hline
\end{tabular}


$g^{\prime}(X, x, y, z, t)$ denotes a variable with zero large scale average, that is, $\overline{g^{\prime}}=0$. Thus, the decomposition in (2.5) separates the dynamic variable into a planetary-scale envelope mean and separate fluctuations on the equatorial synoptic scales.

In the IPESD equations, the temperature, pressure, and velocity have the form

$$
\begin{aligned}
\theta & =\theta^{\prime}(\epsilon x, x, y, z, t)+\bar{\Theta}(\epsilon x, y, z, t)+O(\epsilon) \\
P & =p^{\prime}(\epsilon x, x, y, z, t)+\bar{P}(\epsilon x, y, z, t)+O(\epsilon) \\
U & =u^{\prime}(\epsilon x, x, y, z, t)+\bar{U}(\epsilon x, y, z, t)+O(\epsilon) \\
V & =v^{\prime}(\epsilon x, x, y, z, t)+\epsilon \bar{V}(\epsilon x, y, z, t) \\
W & =w^{\prime}(\epsilon x, x, y, z, t)+\epsilon \bar{W}(\epsilon x, y, z, t) .
\end{aligned}
$$

The expansion in (2.3) is nondimensionalized with the intraseasonal time scale $T_{I}$ as the basic time unit, the equatorial synoptic-scale as the basic unit for $x, y$, and $X=\epsilon x$, the zonal planetary-scale; the height of the troposphere defines the vertical length scale so that vertical motions are much weaker than horizontal motions. The unit of temperature fluctuations is $3 \mathrm{~K}$ on the synoptic and planetary scales; the hydrostatic pressure varies accordingly. The zonal velocity unit for the synoptic, $u^{\prime}$, and planetary scales average, $\bar{U}$, are both $6 \mathrm{~m} \mathrm{~s}^{-1}$. The meridional and vertical velocities differ from the temperature, pressure, and mean zonal velocity in that the synoptic-scale fluctuations, $v^{\prime}, w^{\prime}$ are stronger than the synoptic-scale means, $\epsilon \bar{V}, \epsilon \bar{W}$. The units of the synoptic-scale fluctuations are 6 and $0.03 \mathrm{~m} \mathrm{~s}^{-1}$ for the meridional and vertical velocities, respectively; however, their synoptic-scale means are $O(\epsilon) \approx 0.125$ weaker. All of these scales are summarized in Table 2.

It is assumed here that heating drives both planetaryscale and synoptic-scale circulation. This heating is a superposition of a strong fluctuating component on synoptic scales and a weaker planetary-scale mean,

$$
S^{\theta}=S^{\theta^{\prime}}(\epsilon x, x, y, z, t)+\epsilon \overline{S^{\theta}}(\epsilon x, y, z, t) .
$$

With the above units and choice of $\epsilon$, the synoptic-scale heating fluctuations, $S^{\theta^{\prime}}$, are of order $10 \mathrm{~K} \mathrm{day}^{-1}$ while the mean heating, $\epsilon \bar{S}^{\theta}$, is of order roughly $1.5 \mathrm{~K} \mathrm{day}^{-1}$. These numbers compare well with observations of the MJO (Lin and Johnson 1996; Yanai et al. 2000).

The systematic derivation of the IPESD models from the primitive equations (Majda and Klein 2003) establishes that the fluctuations satisfy the synoptic-scale equatorial weak temperature gradient (SEWTG) equations with zero mean heating on the synoptic scales

$$
\begin{aligned}
-y v^{\prime}+p_{x}^{\prime} & =0 \\
w^{\prime} & =S^{\theta^{\prime}}, \overline{S^{\theta^{\prime}}}=0 \\
y u^{\prime}+p_{y}^{\prime} & =0 \\
p_{z}^{\prime} & =\theta^{\prime} \\
u_{x}^{\prime}+v_{y}^{\prime}+w_{z}^{\prime} & =0 .
\end{aligned}
$$

The SEWTG model differs from traditional MatsunoGill models in the Tropics (Gill 1980; Bretherton and Sobel 2003; Neelin 1989), in that damping, whether thermal, upper tropospheric drag, or lower boundary layer does not affect the synoptic scales. This is consistent with observations that suggest that the fastest dissipation times arise from upper tropospheric damping with a 5-day time scale (Lin and Mapes 2004) and, therefore, the damping will enter at the next order of the theory.

In the IPESD models, the large scale envelope variables satisfy the quasi-linear equatorial long wave equations (QLELWE)

$$
\begin{aligned}
\bar{U}_{t}-y \bar{V}+\bar{P}_{X} & =F^{U}-d \bar{U} \\
\bar{\Theta}_{t}+\bar{W} & =F^{\theta}-d_{\theta} \bar{\Theta}+\overline{S^{\theta}} \\
y \bar{U}+\bar{P}_{y} & =0 \\
\bar{P}_{z} & =\bar{\Theta} \\
\bar{U}_{X}+\bar{V}_{y}+\bar{W}_{z} & =0,
\end{aligned}
$$

which have several interesting features. Note that upper tropospheric drag, $d \bar{U}$, and thermal dissipation, $d_{\theta} \bar{\Theta}$, do affect planetary scales. Their values are such that $d^{-1} \approx 5$ days and the value $d_{\theta}^{-1} \approx 15$ days in dimensional units is chosen as representative of the thermal damping (Bretherton and Sobel 2003). The value used here for momentum dissipation is broadly consistent with current estimates from the observational record (Lin and Mapes 2004) and is routinely used in other studies with the Gill model (Bretherton and Sobel 2003).

The planetary-scale flows are driven by a planetaryscale thermal forcing, $\overline{S^{\theta}}$, as in traditional Matsuno-Gill models with several vertical modes. Additionally, the planetary scales are driven by upscale momentum and temperature fluxes from the synoptic scales. The forcing terms, $F^{U}$ and $F^{\theta}$, are the equatorial synoptic-scale eddy momentum and temperature flux convergence, respectively, and are expressed as

$$
\begin{gathered}
F^{U}=-\overline{\left(u^{\prime} v^{\prime}\right)_{y}}-\overline{\left(u^{\prime} w^{\prime}\right)_{z}} \\
F^{\theta}=-\overline{\left(\theta^{\prime} v^{\prime}\right)_{y}}-\overline{\left(\theta^{\prime} w^{\prime}\right)_{z}} .
\end{gathered}
$$

The first terms in these expressions are the meridional components of the eddy momentum flux convergence and the second terms are the vertical components. Notice that fluctuations in the synoptic-scale heating affect the planetary-scale flows in a nonlinear fashion. Compare two heating profiles on the synoptic scales, $S_{0}^{\theta^{\prime}}=$ $S_{0}(\epsilon x, x, y, z, t)$ and

$$
S_{1}^{\theta^{\prime}}=A S_{0}(\epsilon x, x, y, z, t),
$$

that is, $A$ is the relative amplitude of the heating of the second and first profiles. Since the equations for the synoptic-scale flow are linear in $S^{\theta^{\prime}}$ and the expressions for the flux convergence are quadratic in the synoptic- 
scale variables, then the flux convergence of the two different heating profiles are related by

$$
F_{1}^{U}=A^{2} F_{0}^{U}, \quad F_{1}^{\theta}=A^{2} F_{0}^{\theta} .
$$

Therefore the effective forcing that drives planetaryscale flows is affected by the square of the amplitude of the synoptic-scale heating fluctuations. This is called a quasi-linear model in the applied mathematics literature.

The formulas in (2.5)-(2.7) define the IPESD models used below and a solution strategy goes as follows. Upon specifying the heating profile, $S^{\theta^{\prime}}$, solve the synoptic-scale fluctuation Eqs. (2.5) and calculate the synoptic-scale flux convergence from (2.7); this is done in section 3 for realistic models of heating due to synopticscale organized systems. Since the flux convergences are averaged on synoptic scales, many different synoptic heating profiles, $S^{\theta}$, yield the same flux convergences, $F^{U}, F^{\theta}$ as shown in section 3 . A solution to the planetary-scale flows in Eq. (2.6) consists of a linear superposition of solutions that arise from forcing due to the flux convergences, $F^{U}, F^{\theta}$, and planetary-scale heating, $\overline{S^{\theta}}$, as in a Matsuno-Gill model.

\section{Wave trains of equatorial synoptic-scale circulations in a convective envelope}

Consistent with the interpretation of the MJO as a propagating wave, the heating fluctuations and mean in (2.4) for the IPESD equations are modeled as a moving convective envelope,

$$
\begin{aligned}
S^{\theta}= & F(X-s t)\left[Q^{\prime}(X, x, y, z, t)\right. \\
& +\epsilon \bar{Q}(X, y, z, t)] \\
Q^{\prime}(X, x, y, z, t)= & G_{x}^{1}(X, x, y, t) \sin (z) \\
& +G_{x}^{2}(X, x, y, t) \sin (2 z) \\
\bar{Q}(X, y, z, t)= & S^{1}(X, y, t) \sin (z)+S^{2}(X, y, t) \sin (2 z) .
\end{aligned}
$$

Both observations (Mapes and Houze 1995) and theory (Mapes 2000; Majda and Shefter 2001; Majda et al. 2004) suggest that first baroclinic heating, the term proportional to $\sin (z)$ in $(3.1)$, is ubiquitous in the convective envelope and yields a dominant spectral peak. Also stratiform heating, the term proportional to $\sin (2 z)$ in (3.1), is significant for organized convective activity both on equatorial mesoscales and on equatorial synoptic scales and yields the other significant spectral peak.

The functions $G^{i}$ describe the fluctuations of the deep convective and stratiform heating on the synoptic scales. Through the dependence of $G^{i}$ on $X$, the IPESD models allow for the modulation of synoptic-scale features such as the vertical tilts of organized synoptic convective clusters or the relative strength of the first and second baroclinic heating, over planetary scales. The function $F(X-s t)$ describes an envelope of convection moving eastward at a speed $s$. Since the SEWTG equations in (2.5) make no reference to the zonal planetary scales, $X$, or advection time, $t$, their solutions are linear in $F$ as described in (2.8) and (2.9). The mean heating on planetary scales is weaker than the fluctuating component and is described by the meridionally varying first, $S^{1}$, and second, $S^{2}$, baroclinic heating functions, but from Eq. (2.5) it is clear that it does not contribute to the synoptic-scale fluctuations and need not be discussed until the planetary-scale flows are considered in section 5 .

The exact synoptic-scale solution corresponding to the fluctuating component of the heating in Eq. (3.1) is given by

$$
\begin{aligned}
u^{\prime} & =-\left[\left(2 G^{1}+y G_{y}^{1}\right) \cos (z)+2\left(2 G^{2}+y G_{y}^{2}\right) \cos (2 z)\right] \\
v^{\prime} & =y\left[G_{x}^{1} \cos (z)+2 G_{x}^{2} \cos (2 z)\right] \\
w^{\prime} & =G_{x}^{1} \sin (z)+G_{x}^{2} \sin (2 z) \\
p^{\prime} & =y^{2}\left[G^{1} \cos (z)+2 G^{2} \cos (2 z)\right] \\
\theta^{\prime} & =-y^{2}\left[G^{1} \sin (z)+4 G^{2} \sin (2 z)\right],
\end{aligned}
$$

where $F=1$ has been used, but arbitrary convective envelopes can be considered by exploiting the linearity of SEWTG with respect to the heating discussed above. These relatively general solutions for synoptic-scale flows have the interesting property that, since the SEWTG Eqs. (2.5) describe equatorial geostrophically balanced flows on the synoptic scales, the meridional velocity, temperature, and pressure vanish as latitude goes to zero. This will have important consequences for the resultant upscale fluxes from the eddy flux convergences.

Simple models (Majda and Biello 2004) indicate how the structure of equatorial synoptic convective superclusters can be modeled in a fashion consistent with their observed properties. Following Majda and Biello (2004), it is useful to consider a separable form for the synoptic-scale heating,

$$
\begin{aligned}
Q^{\prime}= & H(y)\{f[x / \lambda-\phi(t)] \sin (z) \\
& \left.-\alpha f\left[\left(x+x_{0}\right) / \lambda-\phi(t)\right] \sin (2 z)\right\},
\end{aligned}
$$

where $f$ must average to zero on synoptic scales. This describes a direct plus stratiform heating profile both with the same meridional structure, $H(y)$, and zonal synoptic structure, $f(x)$. The time varying phase $\phi(t)$ arises, for example, from the observation that convective superclusters propagate eastward within the moving convective envelope at a speed of roughly $15 \mathrm{~m} \mathrm{~s}^{-1}$ (Straub and Kiladis 2003). The ratio of stratiform to deep convective heating is $\alpha$ and a troposphere with greater heating rate at the top has $\alpha>0$. The stratiform heating lags (westward) the deep convective heating if $x_{0}>0$ and leads it otherwise, while $\lambda$ measures the 
typical length scale of the wave packet compared with $1500 \mathrm{~km}$, the equatorial synoptic scale. It is important to establish that within the IPESD model, the upscale fluxes are insensitive to many details of the wave train. Thus, it is useful to consider both localized periodic structures and wavelike structures for the synopticscale fluctuations,

$$
f(x)=\left\{\begin{array}{ll}
e^{-x^{2} / 2}-C_{0} & \text { Localized } \\
\cos (x) & \text { Wave }
\end{array},\right.
$$

where the localized structure is actually a periodic train of Gaussians separated by a distance $2 L_{0}>\lambda$ with $C_{0}$ chosen so as to make their mean zero. The first case in (3.4) with the Gaussian profile in the wave train is skewed with a narrow area for positive values and a wider area for negative values of heating anomalies (see Fig. 1).

A simple meridional profile of the synoptic-scale heating will be used for all of the subsequent examples,

$$
H(y)=H_{0} e^{-\left(y+y_{0}\right)^{2}} .
$$

Therefore synoptic-scale heating is centered at latitudes in the Southern Hemisphere given by $y_{0} ; y_{0}=0,0.3,0.6$ for latitudes of 0,450 , and $900 \mathrm{~km}$ south, respectively, and its strength drops to half of its maximum magnitude at latitudes $1250 \mathrm{~km}$ away from the location of the maximum; these are typical scales seen in observations (Maloney and Hartmann 1998; Houze et al. 2000).

Using Eqs. (3.3) and (2.7), the momentum and temperature flux convergence corresponding to the heating profile in (3.3) is

$$
\begin{aligned}
F^{U}= & \kappa[\cos (z)-\cos (3 z)]\left(2 H^{2}+y H H_{y}\right) \\
F^{\theta}= & -\kappa y^{2}\left\{\sin (z)\left[5 H^{2}+4 y H H_{y}\right]\right. \\
& \left.+\sin (3 z)\left[5 H^{2}+4 / 3 y H H_{y}\right]\right\}
\end{aligned}
$$

where

$$
\kappa \equiv\left\{\begin{array}{ll}
\frac{3}{4} F(X-s t)^{2} \alpha \frac{\sqrt{\pi} \lambda}{L_{0}} x_{0} & \text { Localized } \\
\frac{3}{4} F(X-s t)^{2} \alpha \lambda \sin \left(x_{0} / \lambda\right) & \text { Wave }
\end{array},\right.
$$

and the envelope function $F(X-s t)$ has been restored for completeness. Note that the upscale transports of synoptic-scale waves with first and second baroclinic heating components generate first and third baroclinic components for the planetary-scale eddy fluxes. The expressions for the eddy flux convergences in the two cases differ only in their values of $\kappa$, which can vary only on zonal planetary scales, not in their dependence on latitude and height in the troposphere $(y, z)$. Furthermore, since these expressions have been averaged over the synoptic scales, the dependence of the eddy fluxes on the phase velocity, $\phi(t)$, of the individual synoptic-scale structures drops out of the expression for the fluxes. This calculation demonstrates the insensitivity of the upscale fluxes to details of the wave train.

The explicit analytic form of the heating in Eq. (3.3) and the resultant expression for the eddy flux convergence are both general enough to model the relevant physical phenomena and simple enough to highlight the role of certain essential physical mechanisms. The interesting physical phenomena are westward-tilted deep convective systems organized on synoptic scales and lower troposphere congestus heating. The essential mechanisms are highlighted in the expression for $\kappa$, (3.7): the role of top- or bottom-heavy heating, $\alpha$, and the role of a lagging or leading second baroclinic mode, $x_{0}$. The sign of the eddy fluxes depends on the sign of both of these terms. Clearly the absence of a second baroclinic mode, or the lack of a phase lag in the second baroclinic implies that the eddy flux convergences are zero and there is no upscale transfer of momentum or heat.

The three important examples of synoptic-scale variation that will be used as the basic models of this paper are shown in Fig. 1. The first is a wavelike synoptic-scale disturbance with top-heavy heating and westward tilts; a basic model for organized convective superclusters in the convective envelope. The second model uses the periodic Gaussian with realistic parameters chosen to yield the same eddy flux convergences as the wavelike synoptic structure. The third example is also a periodic synoptic structure, but with bottomheavy heating used to resemble a wave packet anomaly with congestus convection. This example has exactly the negative temperature and momentum flux (due to the negative value of $\kappa$ ) as the previous two. The heating contours and vertical/zonal flow vectors are shown for these three examples in Fig. 1. In the figure, the vertical/zonal slice is taken over the maximum of the heating, $y=-y_{0}$.

To understand the magnitudes of the upscale momentum and temperature fluxes it is useful to interpret the expressions (3.3) and (3.6) in dimensional units. Figure 1a is constructed using equatorially symmetric synoptic-scale heating, $y_{0}=0$, with a first baroclinic mode heating rate of $12 \mathrm{~K} \mathrm{day}^{-1}$ at its maximum, a second baroclinic mode heating rate of $8 \mathrm{~K} \mathrm{day}^{-1}(\alpha=$ $2 / 3$ ) at its maximum, a synoptic-scale wavelength of 950 $\mathrm{km}(\lambda=0.65)$, and a second baroclinic lag of $750 \mathrm{~km}$ (westward tilt, $x_{0}=0.5$ ). The momentum eddy flux convergence, $F^{U}$, produces an acceleration whose maximum is $6 \mathrm{~m} \mathrm{~s}^{-1}$ day $^{-1}$ at a height of $4 \mathrm{~km}$ above the base of the troposphere above the equator. The temperature eddy flux convergence is much weaker, corresponding to a planetary-scale heating rate of $0.6 \mathrm{~K}$ day $^{-1}$ and attains a maximum off equatorially and at midtroposphere. The same eddy flux convergences are attained by the localized convective supercluster model in Fig. 1b for first and second baroclinic heating rate maximum of 12 and $8 \mathrm{~K} \mathrm{day}^{-1}$, respectively, a lag of $2200 \mathrm{~km}$, and a filling fraction, $\lambda / L_{0}=0.27$. Precisely 
(a)

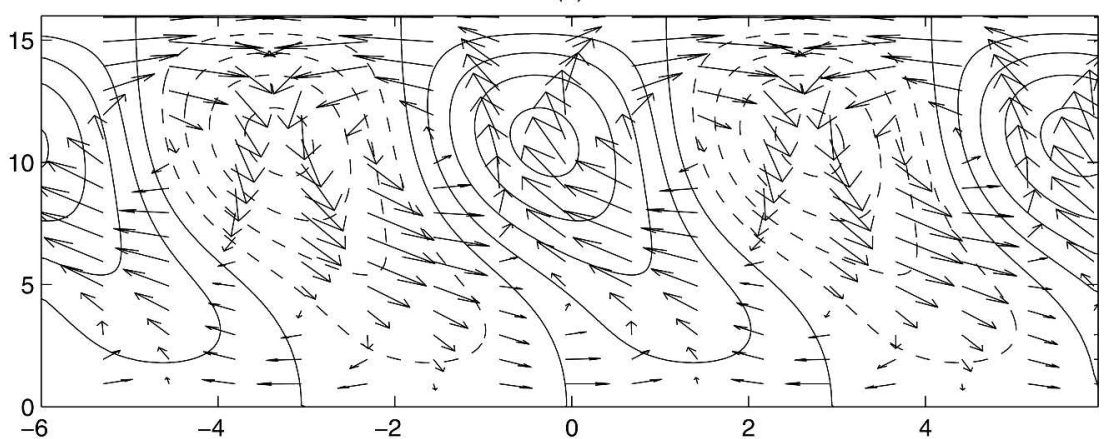

(b)

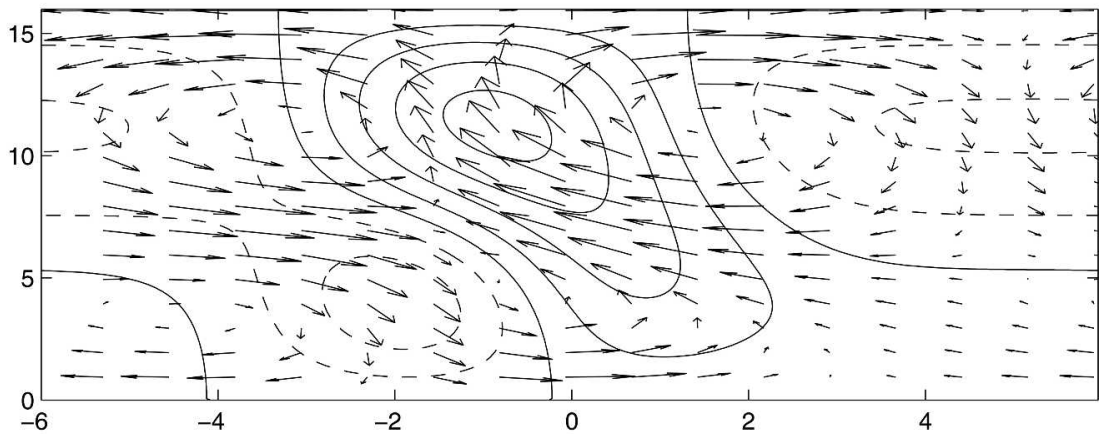

(c)

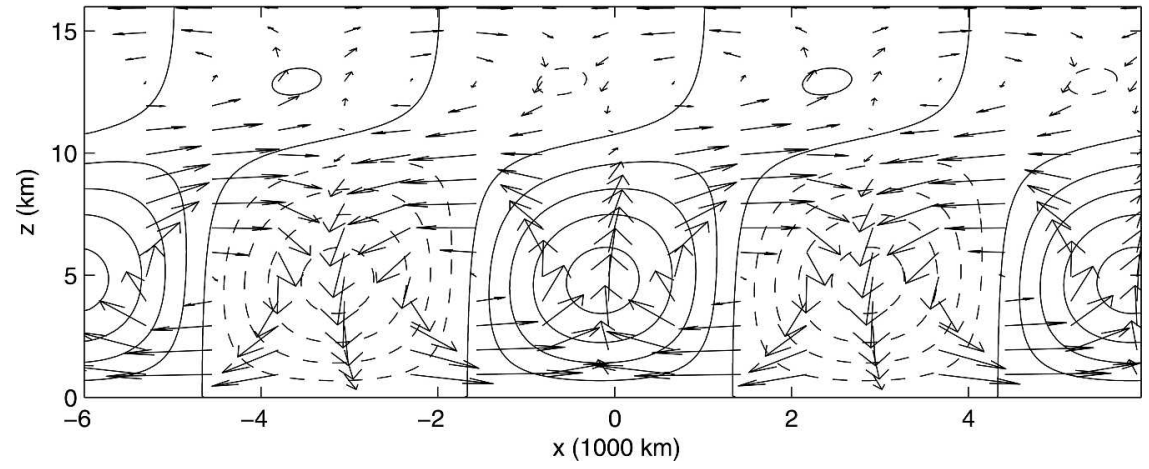

FIG. 1. Contours of synoptic-scale heating, $S^{\theta^{\prime}}$ (solid, positive; dashed, negative) and vectors of zonal/meridional velocity $\left(u^{\prime}, w^{\prime}\right)$ above the latitude of maximum synoptic-scale heating. (a) Wavelike westward-tilted synoptic-scale structures. (b) Localized westward-tilted structure modeling tilted organized convection in the western portion of the convective envelope. (c) A model for congestus heating that yields the negative value of the eddy flux convergences of (a) or (b).

the negative eddy flux convergences of the previous two examples are attained in the example of lower troposphere congestus heating in Fig. 1c. In this case, all the parameters are the same as in the first example except with bottom-heavy heating with a second baroclinic mode of amplitude of $12 \mathrm{~K} \mathrm{day}^{-1}(\alpha=-1)$ and lag $475 \mathrm{~km}\left(x_{0}=0.3\right)$.

The eddy flux convergences for the westward-tilted convective supercluster model (hereafter called the forcing) are shown in Figs. 2-4 for the cases of heating centered at the equator and at latitudes of 450 and 900 $\mathrm{km}$ south; the congestus model has the same flux profiles but the opposite signs. The figures break down these fluxes into the vertical and meridional contributions as defined in Eq. (2.7) and there are several interesting features that are worth noting.

First, from Figs. 2-4 it is clear that the momentum forcing, $F^{U}$, is completely due to the vertical flux of zonal momentum; the meridional flux is everywhere equal to zero. In particular, westward-tilted structures drive westerly winds in the lower troposphere and easterly winds in the upper troposphere. In the equatorially 
(a)

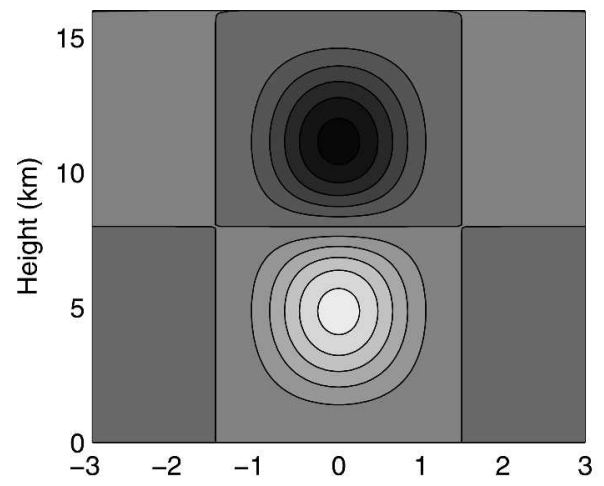

(b)

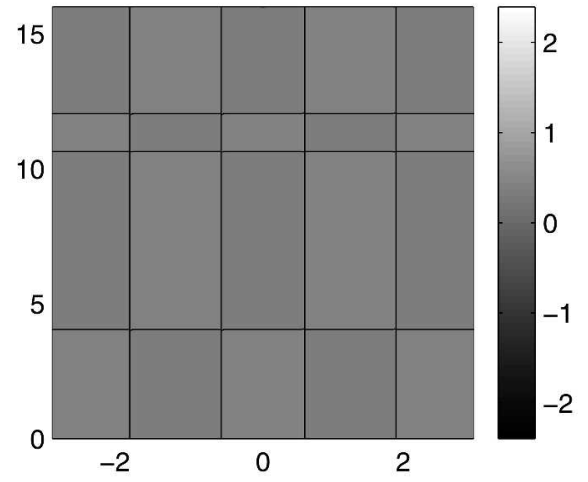

(c)

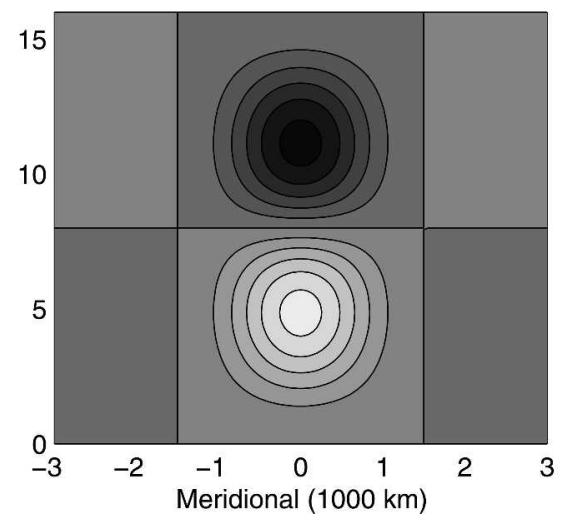

(d)

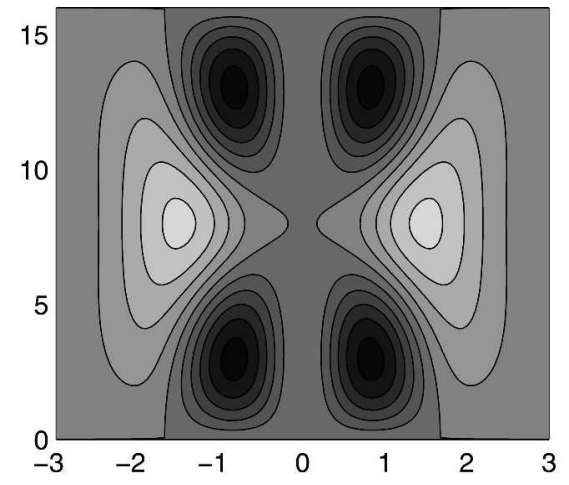

(e)

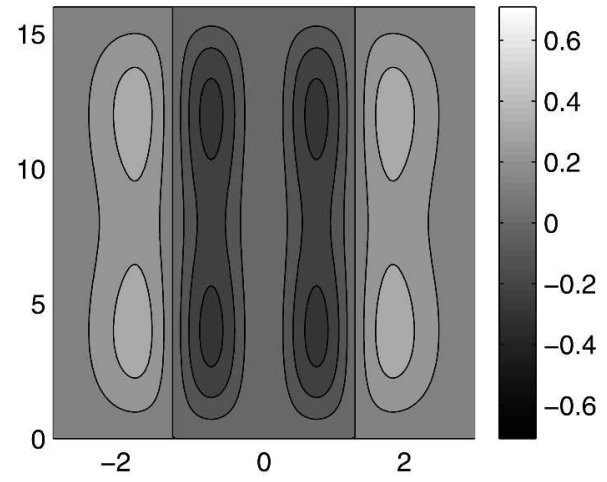

(f)

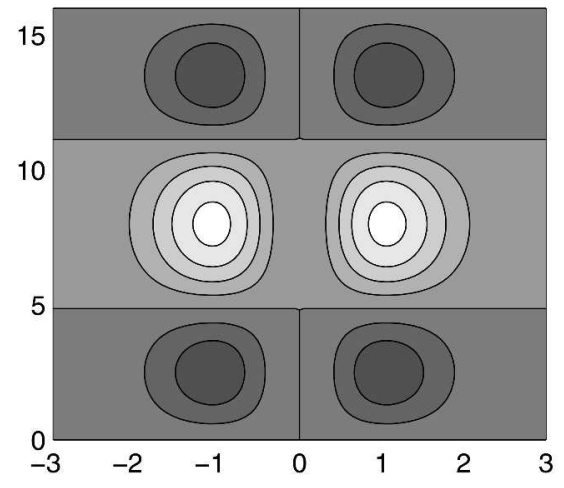

FIG. 2. The eddy flux convergences as a function of latitude and height in the troposphere for equatorially symmetric heating. (a) Total momentum flux convergence, (b) meridional component of momentum flux convergence, (c) vertical component of momentum flux convergence. (d)-(f) Same as (a)-(c) except for the temperature flux convergence. The scale on the left is for (a)-(c) whereas that on the right is for (d)-(f); both are nondimensionalized scales.

symmetric and $450 \mathrm{~km}$ south cases (Figs. 2 and 3), the momentum forcing, $F^{U}$, is everywhere stronger than the thermal forcing, $F^{\theta}$, in nondimensional units. Only in the third example, Fig. 4, does the thermal forcing attain magnitudes comparable to the momentum forcing. In dimensional units, the thermal forcing at midtroposphere at $2500 \mathrm{~km}$ south is about $3 \mathrm{~K}$ day $^{-1}$.

The second point to note is the actual form of the temperature eddy flux divergence. Clearly its strength increases as the synoptic-scale heating moves off the equator. Irrespective of the location of the heating, the thermal forcing is always zero at the equator, this is due to the vanishing of the temperature perturbation, $\theta^{\prime}$, there. In all three cases, the shape of the thermal forcing and its location does not change significantly. The only significant difference is that in the equatorially 
(a)

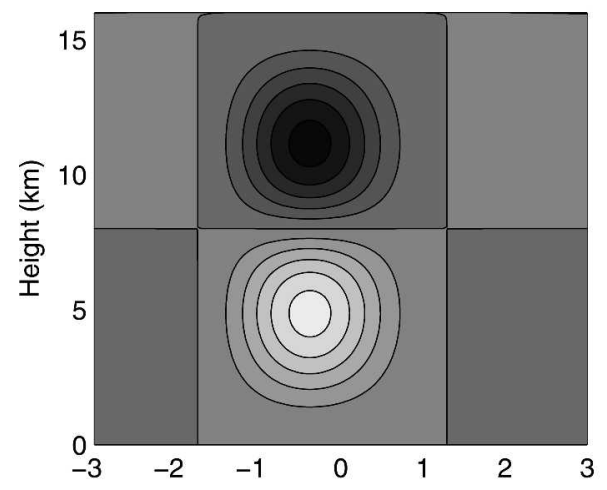

(b)

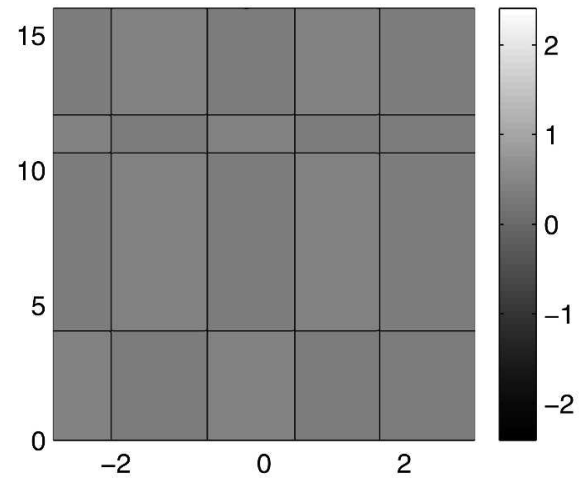

(c)

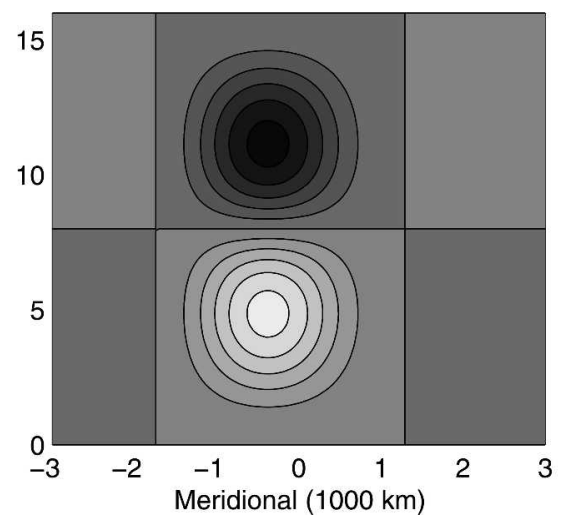

(d)

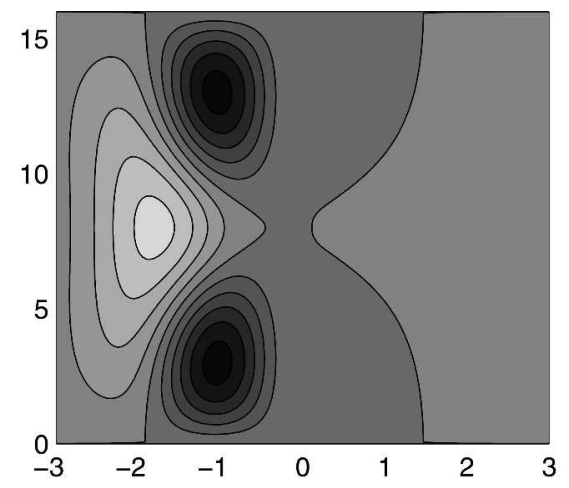

(e)

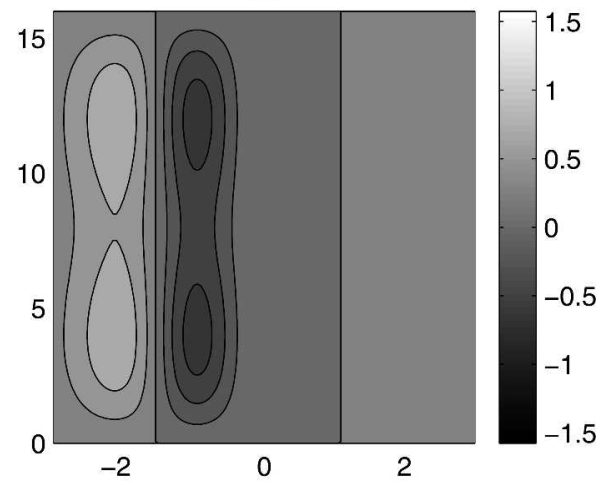

(f)

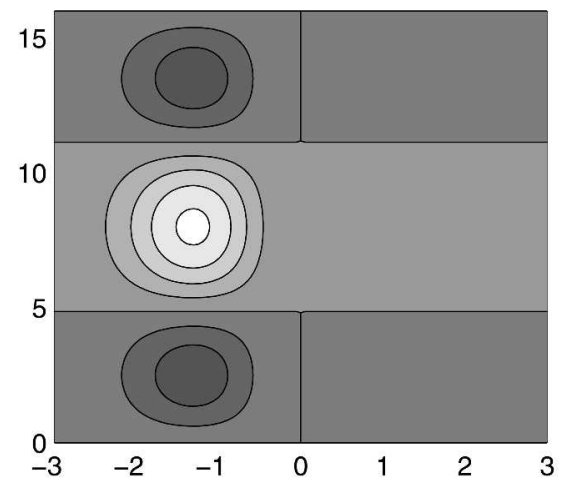

FIG. 3. Same as Fig. 2 except for a heating profile centered at $450 \mathrm{~km}$ south.

symmetric case, the thermal forcing is also symmetric, whereas in the off-equatorial cases, the thermal forcing becomes one sided. Both meridional and vertical fluxes are equally important to the thermal forcing. This yields a force profile that tends to cool the upper and lower troposphere near the equator while heating the middle troposphere away from the equator. Essentially the temperature flux tends to expel heat from the heating region much like the effect of a Hadley cell. Recall that if the tilt were eastward (or if the synoptic structure was that of congestus heating), then the thermal forcing would tend to take heat from the midlatitude middle troposphere and transport it to the upper and lower troposphere nearer the equator.

Finally, note that the parameters describing the tilt, the heating maximum, and the phase speed $\left[x_{0}, \alpha, \phi(t)\right]$ can change over planetary length scales, $X$, and in particular change sign. A negative value of $x_{0}$ corresponds to eastward tilting, that of $\alpha$ to a heating maximum in the lower troposphere and that of $\phi$ to westward- 
(a)

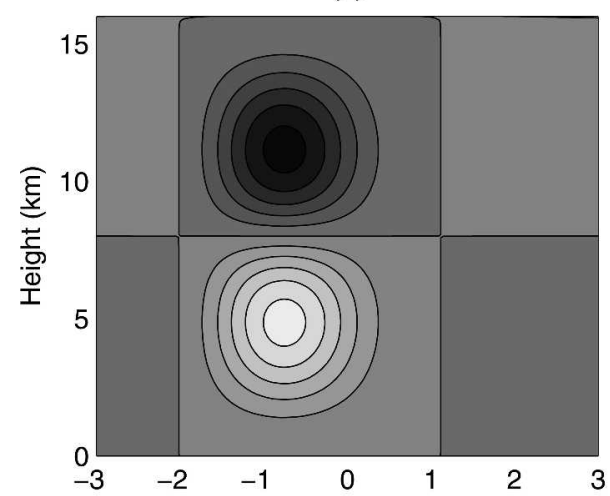

(b)

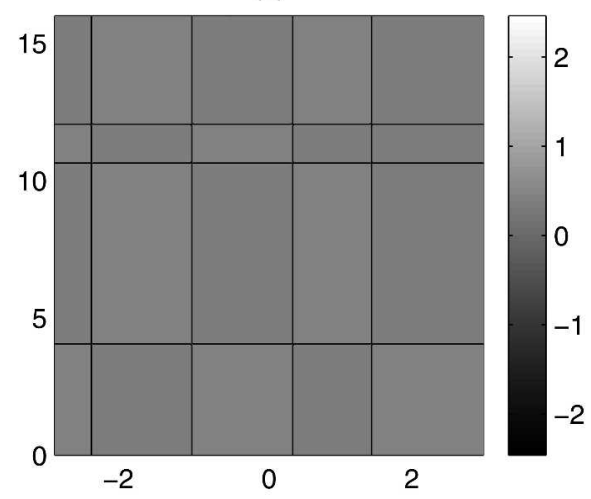

(c)

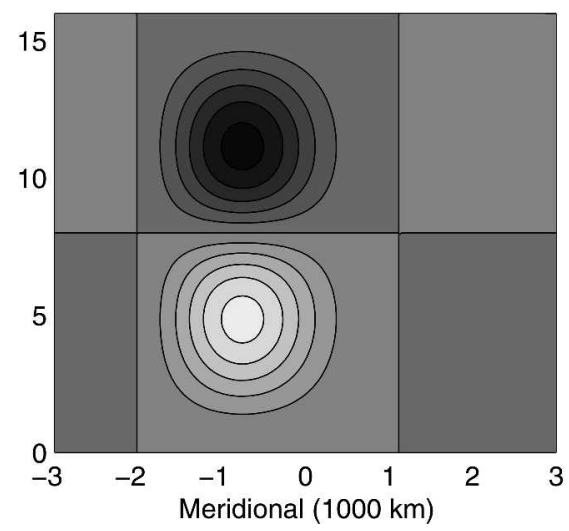

(d)

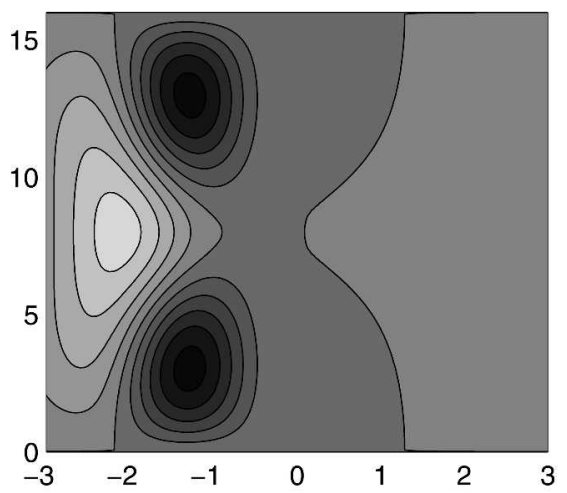

(e)

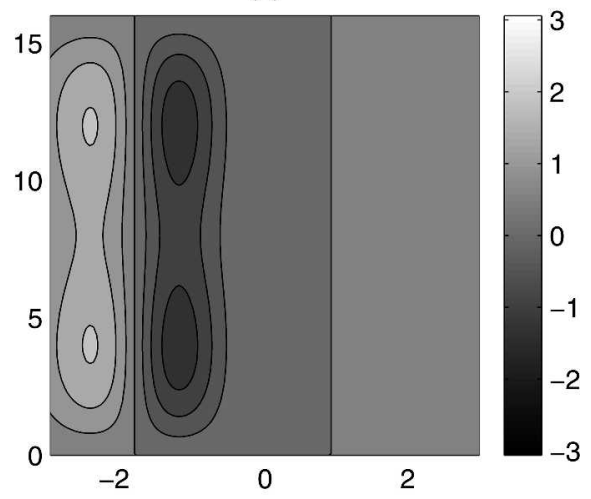

(f)

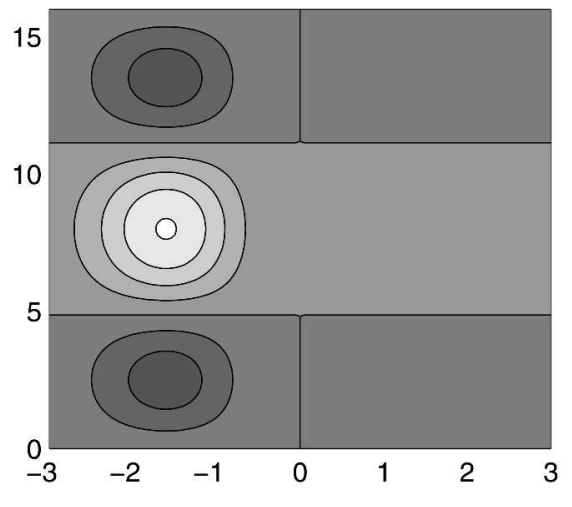

FIG. 4. Same as Fig. 2 except for a heating profile centered at $900 \mathrm{~km}$ south.

propagating synoptic-scale disturbances. These effects are accommodated in the IPESD theory by allowing the parameters or, equivalently, $\kappa$ to vary on the zonal planetary-scale. A particularly interesting case of such variation consists of a convective envelope where westward tilted convective superclusters dominate the western side of the envelope whereas lower troposphere synoptic-scale congestus heating dominates on the eastern side.

\section{The planetary-scale circulation induced by synoptic-scale fluctuations in a moving convective envelope}

In this section, the planetary-scale circulations induced by synoptic heating driving eddy flux divergences in the IPESD model in a moving convective envelope are studied. The objective is to understand the nature of the planetary-scale structures that arise from different 
synoptic-scale heating patterns. Since the envelope of the convective activity within the MJO is observed to travel from the Indian Ocean to the western Pacific, in the following examples and throughout the remainder of the paper, the speed of the convective envelope is prescribed at $5 \mathrm{~m} \mathrm{~s}^{-1}$ which is approximately that of the MJO. The model does not require that the convective envelope move at $5 \mathrm{~m} \mathrm{~s}^{-1}$, or any other velocity. In fact all of the features described in this paper will remain qualitatively the same were the envelope stationary. In the spirit of Chao's (1987) study, we have chosen 5 $\mathrm{m} \mathrm{s}^{-1}$ to reflect the observed fact that the convective activity moves at that rate. Unless otherwise noted, the momentum dissipation time, $d^{-1}$, corresponds to 5 days and the thermal dissipation time, $d_{\theta}^{-1}$, to 15 days. All of the following examples are shown after the planetaryscale flows attain a steady state in the moving frame.

\section{a. The supercluster model}

Westward/upward-tilted superclusters moving eastward within a convective envelope are ubiquitous in the observational record of the MJO (Nakazawa 1988; Wheeler and Kiladis 1999; Wheeler et al. 2000; Straub and Kiladis 2003). The planetary circulation due to a convective envelope consisting of only such westwardtilted superclusters was considered in a previous paper (Majda and Biello 2004) and is described here as a basis of comparison with the other models.

The supercluster model (SC) uses synoptic-scale heating centered at the equator with a synoptic-scale structure as in Figs. 1a or 1b. In this model, the only source of forcing is the eddy flux convergence whose vertical/meridional profile is shown in Fig. 2; the planetary mean heating, $\overline{S^{\theta}}$ is everywhere zero. Recall the main features of the eddy flux convergences. First, westerly momentum is transported downward to the lower midtroposphere, and concentrated about the equator. Second, the temperature fluxes are much weaker than the momentum fluxes and tend to transport heat away from the equator. Finally, the phase speed of the superclusters, observed to be about 15 $\mathrm{m} \mathrm{s}^{-1}$ eastward, plays no role in forcing the planetary circulation.

In the SC model, the eddy flux convergences are modulated over the planetary scales through a moving envelope of convective activity in the spirit of traditional Matsuno-Gill models (Gill 1980; Chao 1987; Bretherton and Sobel 2003; Neelin 1989),

$$
\begin{aligned}
F(X-s t) & =\cos \left[\frac{\pi(X-s t)}{2 L_{F}}\right]^{+} \\
\alpha & =\frac{2}{3},
\end{aligned}
$$

where in dimensional units $s=5 \mathrm{~m} \mathrm{~s}^{-1}$ is the velocity of the convective envelope and $L_{F}=5000 \mathrm{~km}$ is the halfwidth of the envelope. The cosine in Eq. (4.1) is clipped over its first positive range, that is, $\cos (\phi)^{+}=\cos (\phi)$ for $|\phi|<\pi / 2$, and $\cos (\phi)^{+}=0$ for $|\phi| \geq \pi / 2$, and the relative strength of the second baroclinic heating yields upper troposphere (and westward tilted) superclusters as in Figs. 1a and 1b.

In Fig. 5, the planetary-scale circulation of the SC model and the pressure contours at heights of $0,2,4$, and $12 \mathrm{~km}$ above the base of the troposphere are shown. Figure 6a shows the zonal velocity as a function of height and longitude away from the center of the envelope at $X=0$ above the latitude of the maximum of the heating (in this case, the equator). Figure $6 \mathrm{~b}$ shows zonal velocity as a function of height observed at the longitudes of the vertical cuts seen in Fig. 6a. Notice that since the eddy fluxes in these models only drive the first and third baroclinic modes, the flow is antisymmetric about the middle of the troposphere, as is clear from Figs. 5c, 5d, and 6 .

The figures indicate that the SC model has several properties in common with an MJO westerly wind burst, but also some significant differences. The most prominent similarity with observations is that the zonal velocity attains a maximum westerly velocity at heights of $5 \mathrm{~km}$ and west of the center of the convective envelope, decreasing downward within the troposphere. However, at the base of the troposphere, there are only very weak westerlies, which occur west of the envelope of convective activity. There is a clear dipolar Rossby gyre away from the equator on the western side of the convective activity, but the eastern side has only weak vortical flows. Furthermore, there are neither significant winds within the eastern portion of the convective envelope nor east of the convective activity. Lastly, there is a conspicuous lack of vertical tilt in the westerly winds in this model: the westerlies begin at about $5 \mathrm{~km}$ and encroach to the middle and bottom of the troposphere and then die out after the wave passes. Clearly westward-tilted synoptic-scale superclusters alone are insufficient to describe all of the planetary-scale features of an MJO.

\section{b. The congestus/supercluster model}

Recent observations (Johnson and Lin 1997; Houze et al. 2000) suggest that the convective activity during a westerly wind burst has more structure than simply superclusters. In particular, Houze et al. (2000) identify two distinct regions within the westerly wind burst: the "westerly onset region," which is strongly correlated with lower troposphere congestus heating, and the "strong westerly region," which is correlated with convective superclusters. This suggests a model of convection that contains congestus convection on the eastern side of the moving envelope and supercluster activity on the western side.

In this, the congestus/supercluster model $(\mathrm{C} / \mathrm{SC})$, the convective envelope of the SC model is further modulated by a change in the height of the heating maximum on planetary scales. The eastern half has lower tropo- 
(a) $0 \mathrm{~km}, U_{\max }=1.2618$

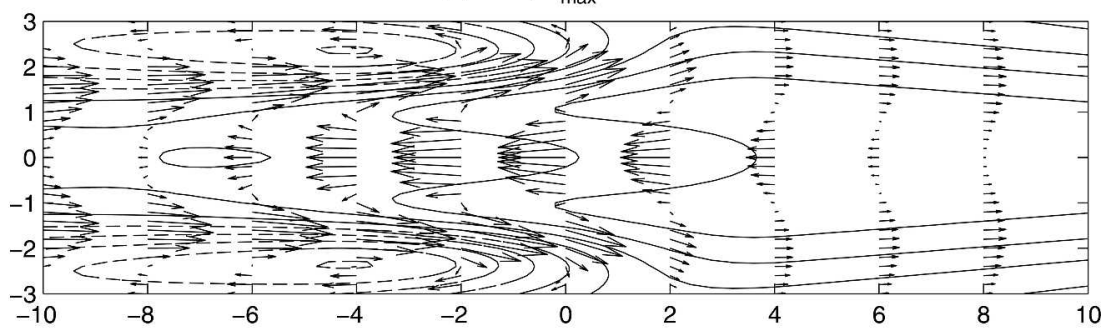

(b) $2 \mathrm{~km}, \mathrm{U}_{\max }=2.7126$

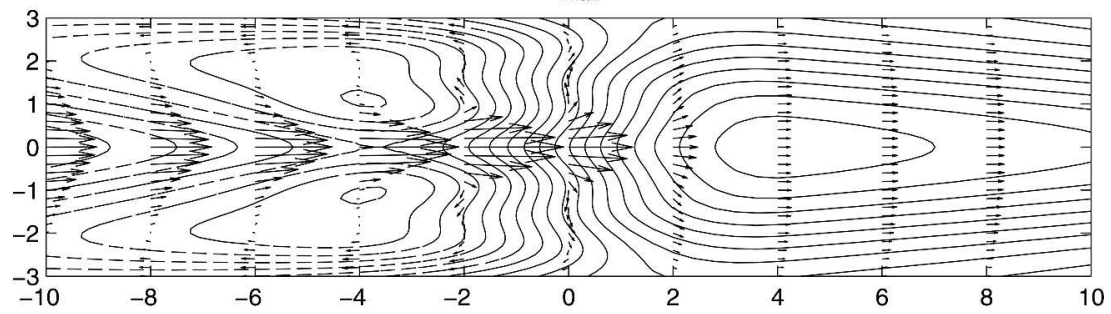

(c) $4 \mathrm{~km}, \mathrm{U}_{\max }=8.3874$

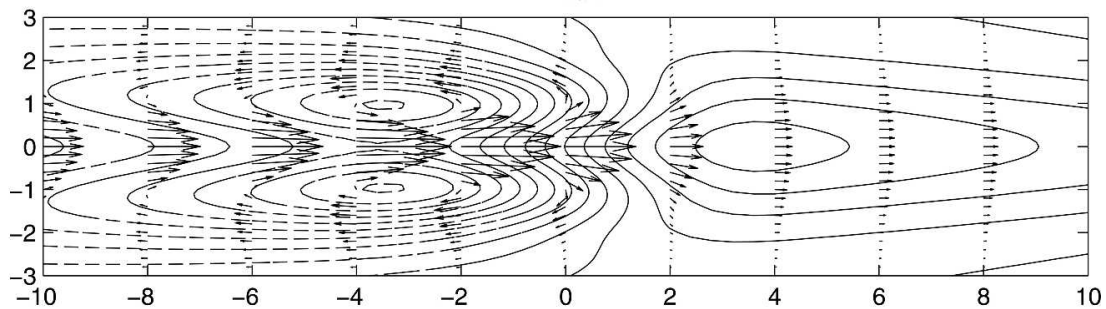

(d) $12 \mathrm{~km}, \mathrm{U}_{\max }=8.3874$

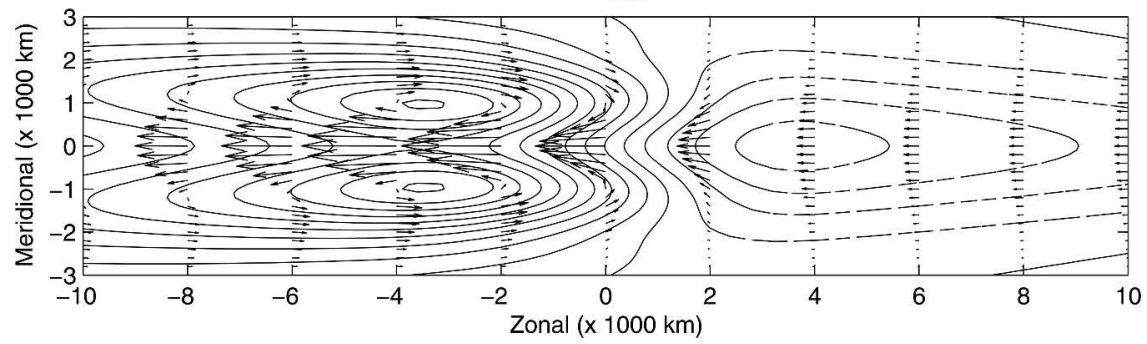

FIG. 5. Planetary-scale response to equatorially symmetric synoptic-scale heating. The panels show flow vectors, solid curves show positive pressure perturbations, dashed curves show negative pressure perturbations at heights (a) 0, (b) 2, (c) 4, and (d) $12 \mathrm{~km}$. Vectors and contours are scaled relative to the maximum at each height; the maximum velocities at each height are (a) 1.3, (b) 2.7, and (c), (d) $8.4 \mathrm{~m} \mathrm{~s}^{-1}$.

sphere, congestus synoptic-scale heating with $\alpha<0$ from Eq. (3.7) corresponding to the structures in Fig. 1c. The western half has westward-tilted superclusters with $\alpha>0$ corresponding to the structures in Fig. 1b. The envelope profile and $\alpha$ both move at $5 \mathrm{~m} \mathrm{~s}^{-1}$ so that

$$
\begin{aligned}
& F(X-s t)=\cos \left[\frac{\pi(X-s t)}{2 L_{F}}\right]^{+} \\
& \alpha(X-s t)=-\frac{8(X-s t)}{3 L_{F}},
\end{aligned}
$$

where the factor in $\alpha$ is chosen so that the maximum of $\alpha F^{2}$ (equivalently of $\kappa$ ) is the same as in the SC model. Recall from the discussion at the end of section 3 that superclusters and congestus synoptic heating need not move at the same phase speed within the envelope. The model can accommodate the observation that, while superclusters propagate eastward, congestus heating tends to propagate westward (Houze et al. 2000), therefore a different phase speed, $\phi(t)$, can be specified in each half of the envelope but does not affect the value of $\kappa$ from Eq. (3.7). The final result is a value of $\kappa$, 
(a)

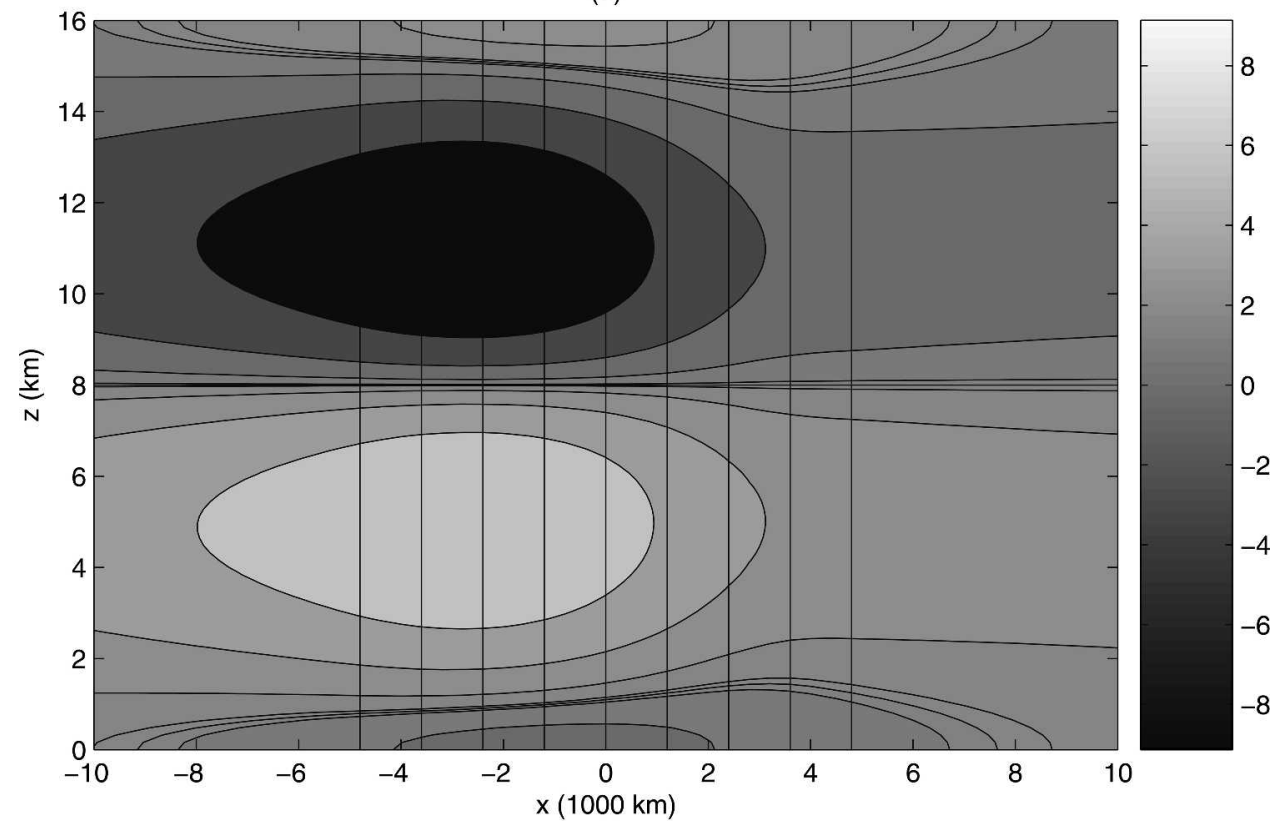

(b)

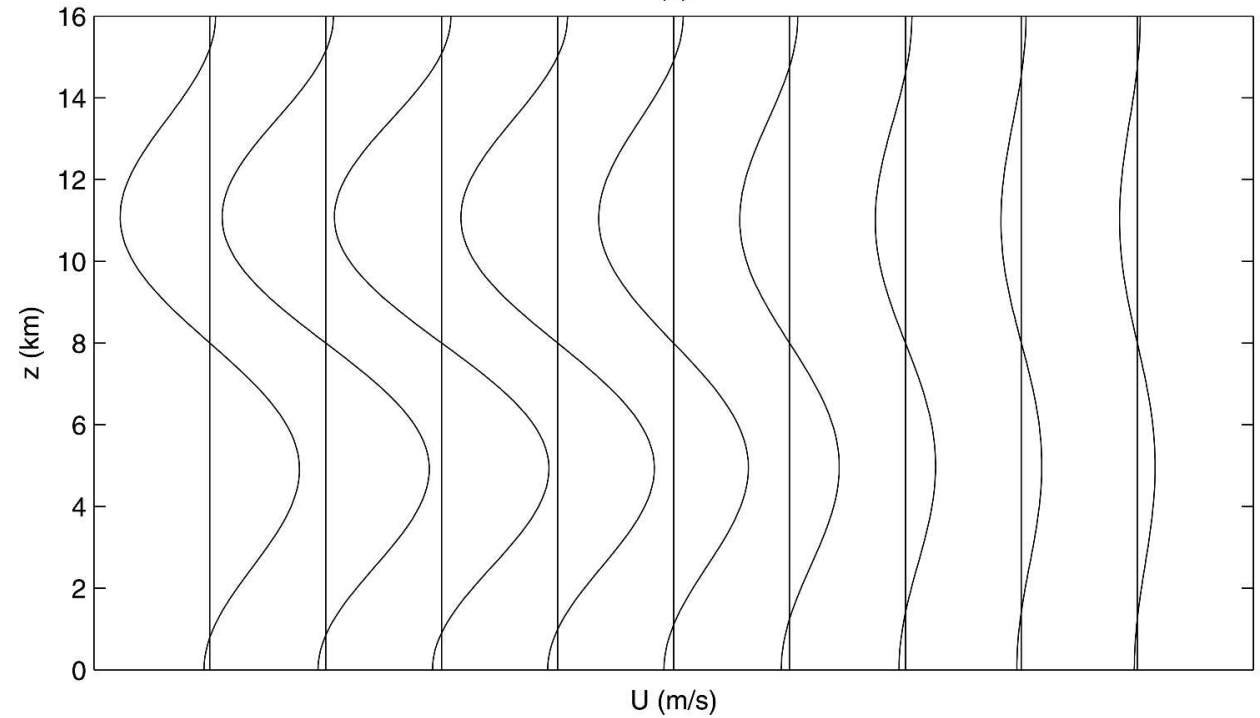

FIG. 6. Equatorially symmetric synoptic-scale heating: (a) contours of zonal velocity: dense contours show transition from westerly (positive) to easterly (negative) winds. The scale is in $\mathrm{m} \mathrm{s}^{-1}$. (b) Height vs zonal velocity taken along each of the vertical cuts shown in (a). The separation of the vertical lines measures $10 \mathrm{~m} \mathrm{~s}^{-1}$.

which is negative in the eastern and positive in the western side of the moving convective envelope.

The resultant flow is shown in Figs. 7 and 8 and has a dramatically different structure than the SC model. Note the presence of a quadrupolar cyclone/anticyclone pair. It will be shown in section 6 that this tendency is much more consistent with observations than the gyres of the SC model (Majda and Biello 2004). As in the SC model, the Rossby gyres lie to the west of the convec- tive envelope, however in $\mathrm{C} / \mathrm{SC}$ there is a pair of anticyclones in the lower troposphere that are centered over the convective envelope; these are most evident above heights of $2 \mathrm{~km}$ as in Figs. $7 \mathrm{~b}$ and $7 \mathrm{c}$.

At the base of the troposphere, the flow is very weak and the anticyclones turn again near the equator and yield westerly winds ahead (to the east) of the convective activity; conversely, easterlies dominate to the west of the moving envelope. This tendency in the very weak 
(a) $0 \mathrm{~km}, \mathrm{U}_{\max }=0.69386$

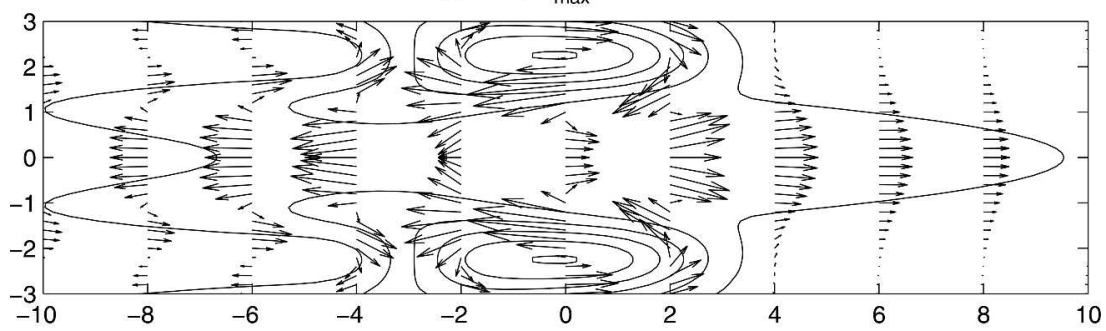

(b) $2 \mathrm{~km}, \mathrm{U}_{\max }=1.5417$

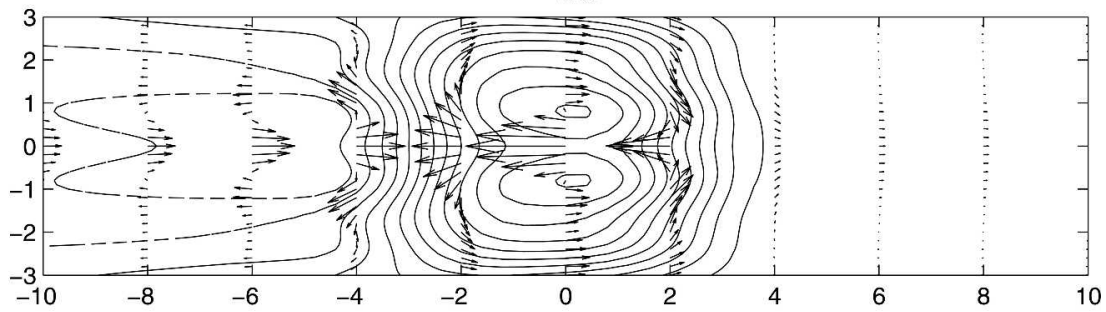

(c) $4 \mathrm{~km}, \mathrm{U}_{\max }=4.4429$

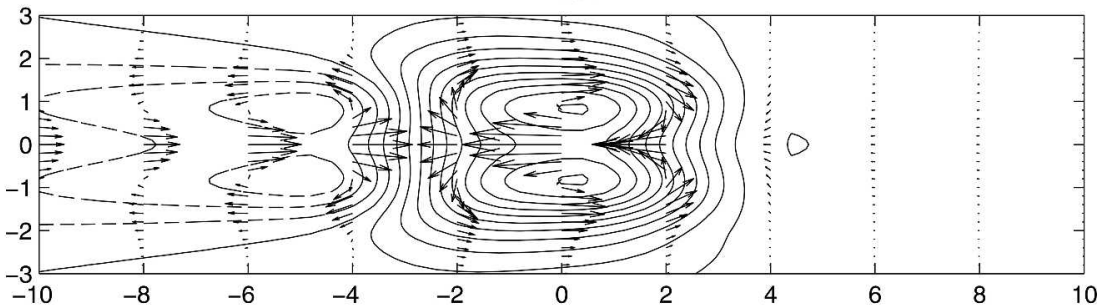

(d) $12 \mathrm{~km}, \mathrm{U}_{\max }=4.4429$

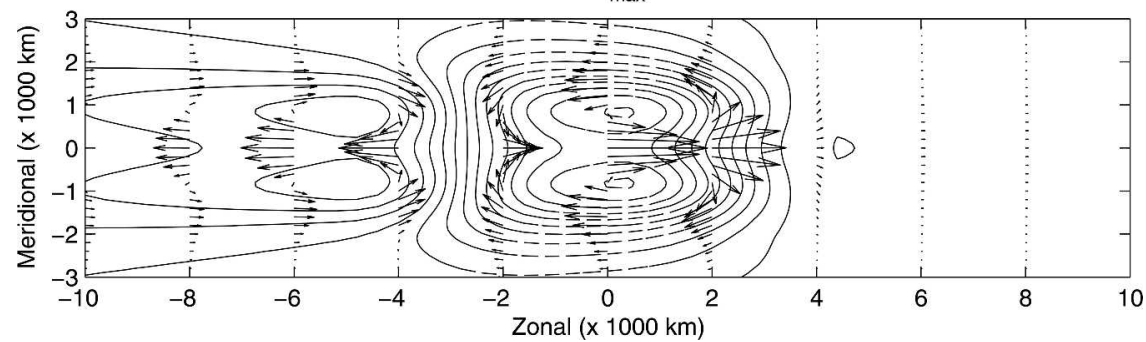

FIG. 7. Same as Fig. 5 for the case of congestus/supercluster synoptic-scale heating. The maximum velocities at each height are (a) 0.7 , (b) 1.5 , and (c), (d) $4.4 \mathrm{~m} \mathrm{~s}^{-1}$. Note that the flow at the bottom of the troposphere (and therefore the pressure perturbation) is very weak so that the detail structure depicted there is misleading.

flow is in sharp distinction to observations and the SC model. At higher levels in the lower half of the troposphere, westerlies dominate to the west of the convective activity and west of $-3000 \mathrm{~km}$ whereas easterlies dominate the rest of the convective region. Since the flow is again antisymmetric about the middle troposphere, at $12 \mathrm{~km}$ the westerlies/easterlies switch direction and the winds are suggestive of an upper troposphere outflow there.

The zonal velocity above the equator shown in Fig. 8 has a strikingly large degree of symmetry. In particular, easterlies overlie westerlies to the west and the roles are reversed in the east. This tendency very much reflects the zonal momentum eddy flux convergence, $F^{U}$, which itself has easterlies overlying westerlies to the west and westerlies overlying easterlies to the east and is a further indication of the negligible role of thermal eddy flux convergence in this model. Though the convective envelope is centered about $X=0$ in Fig. 8, the transition from westerlies to easterlies in the lower half troposphere occurs at about $3000 \mathrm{~km}$ west of the center of convective activity and westerlies clearly enter ver- 
(a)

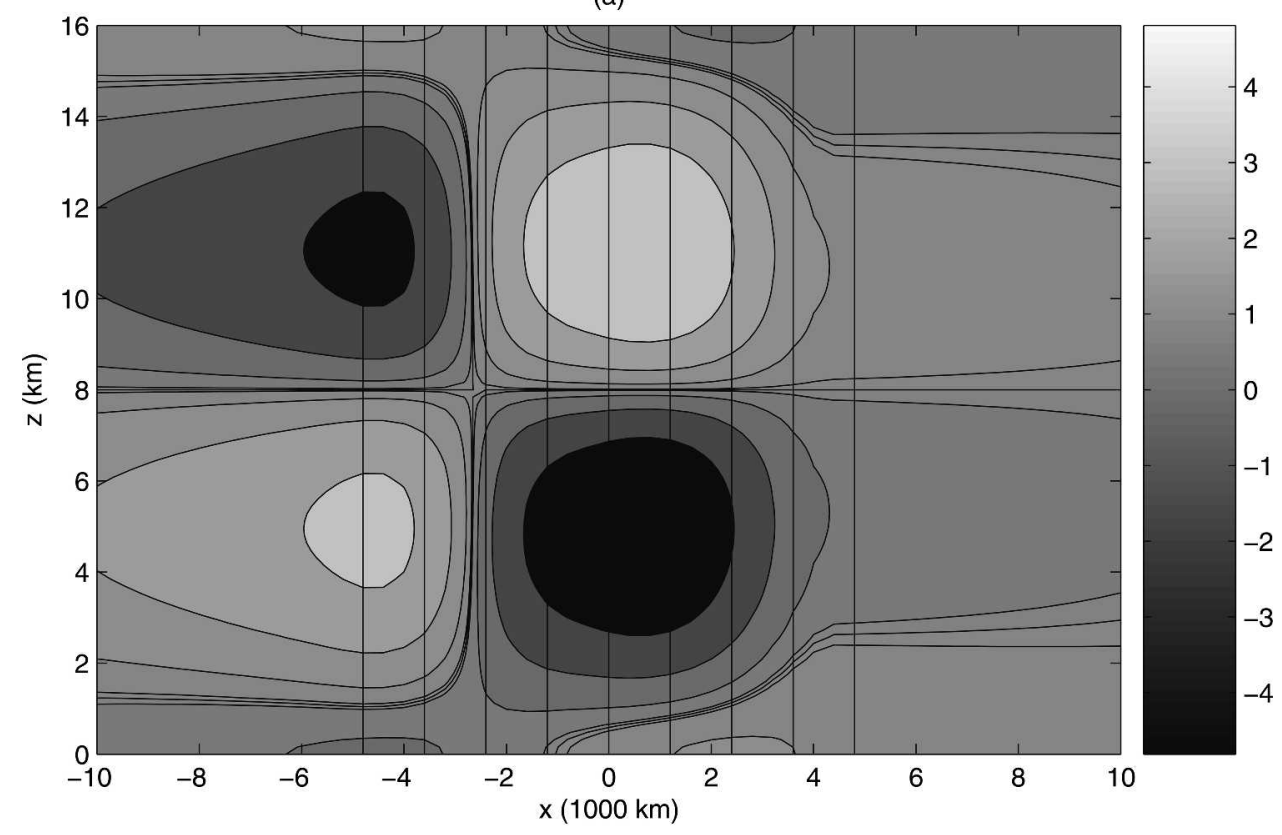

(b)

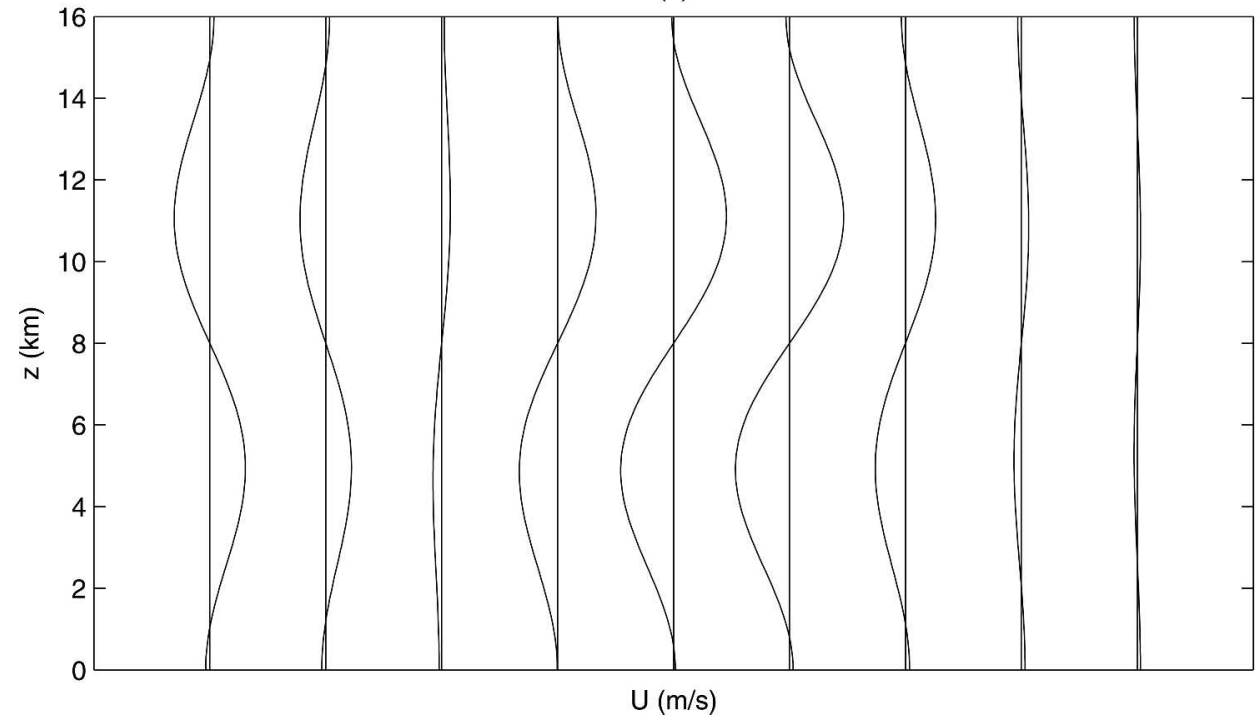

FIG. 8. Same as Fig. 6 for the case of congestus/supercluster synoptic-scale heating.

tically, with no tilt. Finally, there is almost no flow at all to the east of the convective activity; a fact that is again in stark contrast to the SC model.

\section{c. Sensitivity to thermal dissipation}

Matsuno-Gill (Matsuno 1966; Gill 1980) and ad hoc weak temperature gradient models (Neelin 1989; Bretherton and Sobel 2003) are driven by planetaryscale thermal forcing alone and are thereby very sensitive to the choice of thermal dissipation time. It has already been shown that the thermal eddy flux convergence is much smaller than the momentum flux conver- gence in the case of equatorially symmetric convective envelopes and it would be reasonable to expect that the planetary-scale flow solely caused by upscale eddy flux is relatively insensitive to the thermal dissipation and this is the case although, for brevity, these results are not shown here.

\section{$d$. The planetary response from an off-equatorial moving convective envelope}

During the Tropical Ocean Global Atmosphere Coupled-Atmosphere Response Experiment (TOGA COARE) intensive observing period, a particularly 
(a) $0 \mathrm{~km}, \mathrm{U}_{\max }=2.1367$

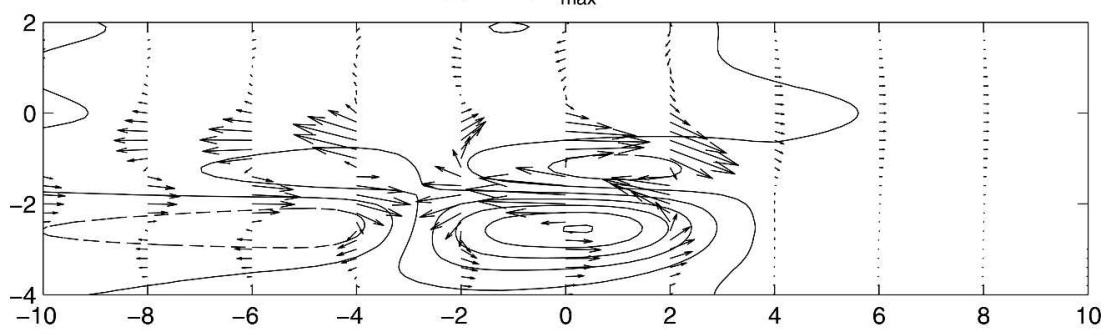

(b) $2 \mathrm{~km}, \mathrm{U}_{\max }=1.0481$

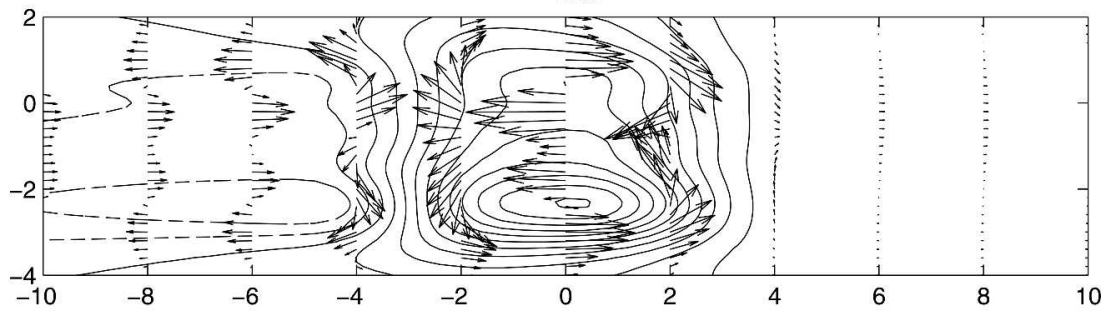

(c) $4 \mathrm{~km}, \mathrm{U}_{\max }=5.1449$

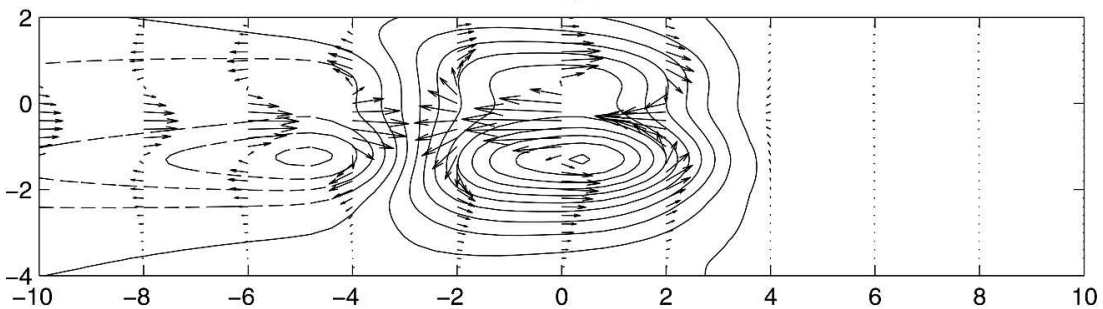

(d) $12 \mathrm{~km}, \mathrm{U}_{\max }=5.1448$

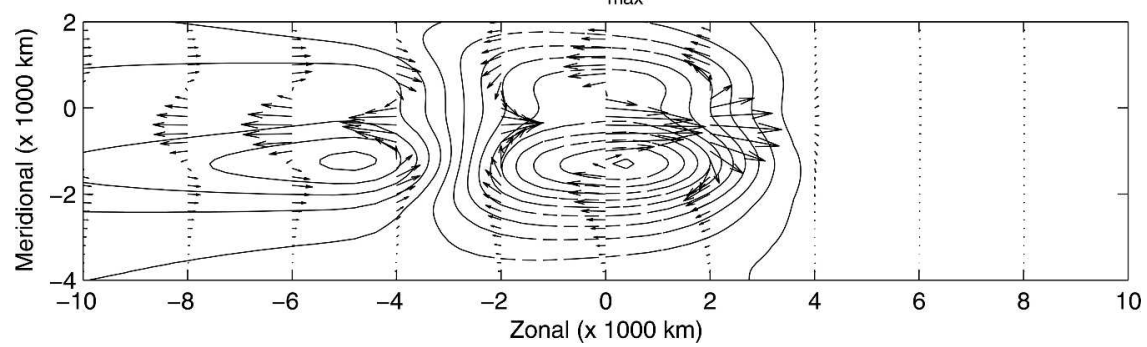

FIG. 9. Same as Fig. 5 for the case of congestus/supercluster synoptic-scale heating centered at $450 \mathrm{~km}$ south. The maximum velocities at each height are (a) 2.1, (b) 1.0, and (c), (d) $5.1 \mathrm{~m} \mathrm{~s}^{-1}$.

well-resolved westerly wind burst occurred a few degrees south of the equator during the austral summer (Lin and Johnson 1996; Yanai et al. 2000) which, along with other MJO observations suggests that seasonal variations in convective activity also affect the planetary-scale flows. Thus it is interesting to also consider synoptic-scale heating which is not equatorially symmetric in the present model.

The planetary-scale flows in Figs. 9 and 10 result from the $\mathrm{C} / \mathrm{SC}$ model with a 15-day thermal dissipation time, 5-day momentum dissipation time, and heating in a moving convective envelope centered at $450 \mathrm{~km}$ south of the equator. A distinct asymmetry in the vorticity arises at the base of the troposphere (Fig. 9a). Where there were symmetric quadrupoles in the equatorially symmetric heating model, stronger flows occur for the quadrupole gyre to the south of the heating and weaker gyres to the north in the quadrupole structure (Yanai et al. 2000). The winds are also much stronger in this case, though the strengthening is concentrated off of the equator. At the higher levels of the troposphere, though the northern part of the quadrupole weakens, there is otherwise very little quantitative change in either the pressure or velocity field. The vertical zonal velocity profile above the heating ( $450 \mathrm{~km}$ south) in Fig. 10 shows little difference with its counterpart in 
(a)

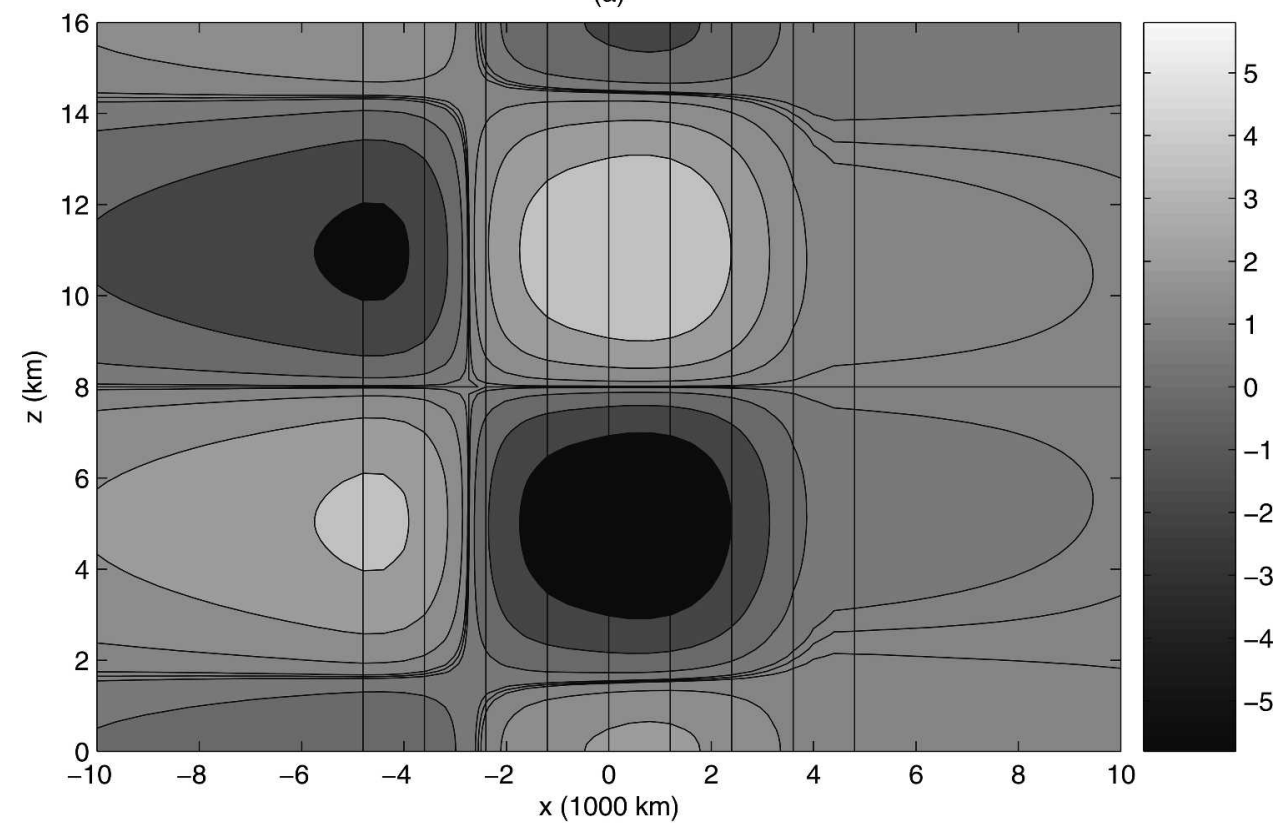

(b)

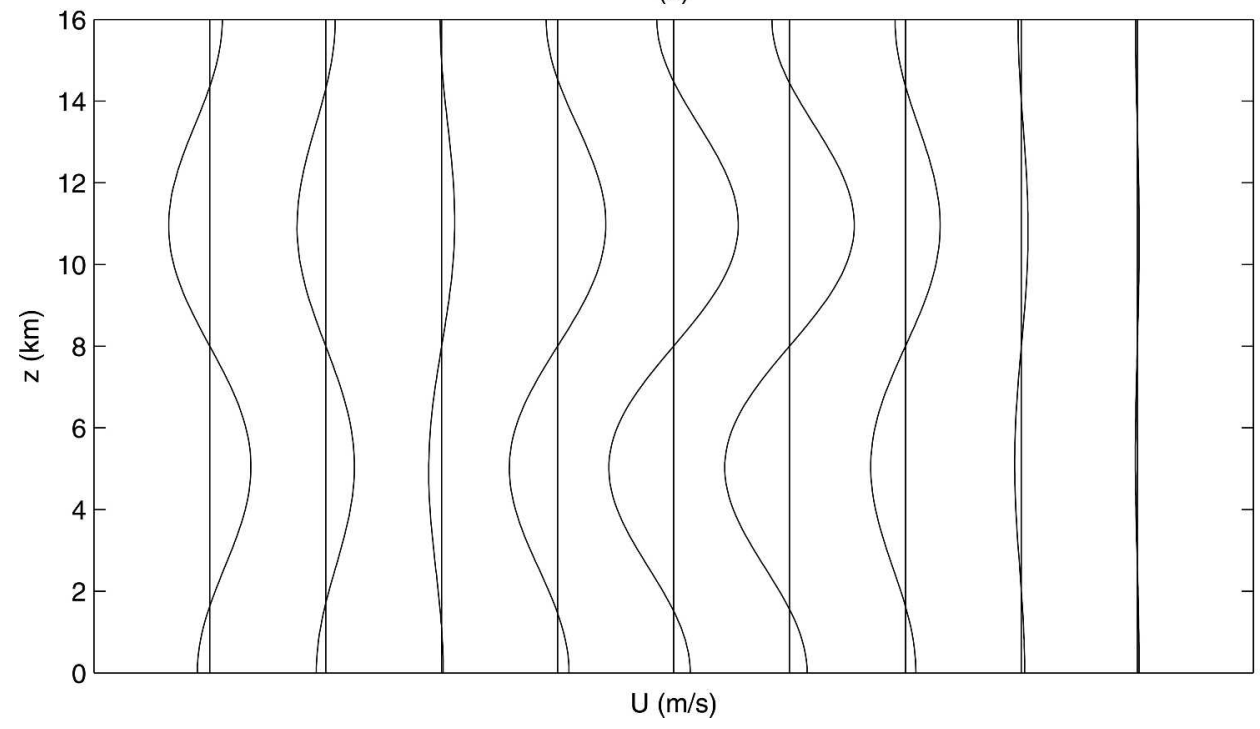

FIG. 10. Same as Fig. 6 for the case of congestus/supercluster synoptic-scale heating centered at 450 $\mathrm{km}$ south.

Fig. 8; in particular, the easterly/westerly transition occurs at the same longitude of $3000 \mathrm{~km}$ behind the center of convective activity.

\section{The planetary-scale circulations induced by mean heating in a moving convective envelope}

The simplest model for planetary-scale circulation in an MJO is the flow driven by a planetary-scale heat source moving at a prescribed speed in a Gill model (Chao 1987). In the IPESD theory, this corresponds to a direct heating component on the large scales, $\overline{S^{\theta}}$, of order a few kelvin per day in the equations in (2.6). In this section, models for the mean heating, $\overline{S^{\theta}}$, in (2.6) are considered alone and the eddy flux contributions, $F^{U}, F^{\theta}$, in (2.6) are set to zero, that is, $F^{U}=F^{\theta}=0$. Of course, since the heating associated with the upscale eddy flux convergence is due to synoptic-scale variations, these synoptic-scale structures should also contribute to the mean heating. Therefore, for consistency in the models developed below, the planetary-scale envelopes of the mean heating correspond to those of the synoptic-scale fluctuations discussed in section 4 . 


\section{a. Models for the mean heating}

This section considers two examples of planetary mean heating, the standard mean heating (SMH) model and the congestus/supercluster mean heating model (C/SCMH). From Eq. (3.1), the planetary-scale mean heating is given by a superposition of first and second baroclinic modes modulated by a moving envelope $F(X-s t)$.

The standard mean heating model ( $\mathrm{SMH})$ is simply a generalization of the classical Matsuno-Gill models including a second baroclinic mode with the same meridional profile as the first. The heating profile is

$$
\overline{S^{\theta}}=F(X-s t) H(y)\left[\sin (z)-\frac{\sin (2 z)}{2}\right],
$$

where $H(y)$ is given by Eq. (3.5). The envelope itself is the same as that used by Gill (1980) and in the upscale eddy flux models of the previous section, it is given by

$$
F(X-s t)=\cos \left[\frac{\pi(X-s t)}{2 L_{F}}\right]^{+} .
$$

For $H_{0} \approx 2$ and $y_{0}=0$ The direct heating in (5.1) is top heavy and reaches a maximum rate of about $3 \mathrm{~K}$ day ${ }^{-1}$ at a height of about $10.5 \mathrm{~km}$. This model is the completely natural candidate for the mean heating arising from a train of superclusters; this is the additional mean planetary-scale heating for the IPESD models in (2.6) that should be added to the fluctuating heating of the SC model described in (4.1).

The second model, $\mathrm{C} / \mathrm{SCMH}$, is the natural candidate for mean heating associated with an envelope of synoptic-scale fluctuations described by (4.2) with congestus heating on the eastern side of the moving convective envelope and upper troposphere supercluster heating on the western side. Again, the heating takes the form of two baroclinic modes

$$
\overline{S^{\theta}}=F(X-s t) H(y)[\sin (z)-\bar{\alpha}(X-s t) \sin (2 z)],
$$

but with the second mode modulated on the planetary scales,

$$
\bar{\alpha}(X-s t)=-\frac{3(X-s t)}{2 L_{F}}
$$

in a fashion similar to Eq. (4.2). For the same parameters as in the $\mathrm{SMH}$ model, this profile interpolates between upper troposphere heating in the western half of the moving convective envelope to lower troposphere heating in the eastern half. For simplicity and consistency, the C/SCMH model uses the same planetary-scale envelope as in all previous cases, $F(X-s t)$ is given by Eq. (5.2).

\section{b. The planetary-scale response to mean heating}

The circulation of the SMH model is shown in Figs. 11 and 12. In the SMH model there are westerlies within the convective envelope and easterlies leading the convective envelope near the equator at the base of the troposphere. However, these winds are much smaller than the higher latitude easterlies that dominate at all longitudes (Fig. 11a). Though a Rossby-gyre pair is evident to the west of the convective envelope, there is no quadrupole in the SMH model, nor is there any outflow from the convective envelope at high altitudes. There is a slight upward/westward tilt in the lower troposphere westerlies, as indicated in Fig. 12. However, since the SMH heating is concentrated in the upper troposphere, the resultant flows in the lower troposphere are very weak and not reminiscent of an MJO westerly wind burst.

The $\mathrm{C} / \mathrm{SCMH}$ model has a heating profile that is reminiscent of the congestus precursor and trailing superclusters observed during westerly wind bursts (Johnson and Lin 1997; Houze et al. 2000). The planetary-scale westerlies (Fig. 13) have a clear westward tilt in good agreement with observations (Lin and Johnson 1996) and trail easterlies at the base of the troposphere. The trailing Rossby gyres and the leading upper-troposphere westerlies are also seen in the observational record. However, there is clearly no horizontal quadrupolar structure in either of the direct heating examples, nor is there the coincident uppertroposphere outflow from the heating region as is seen in the $\mathrm{C} / \mathrm{SC}$ model. The observations also indicate that in the strong westerly region, the westerly wind bursts reach a maximum at heights of about $4-6 \mathrm{~km}$ above the base of the troposphere and this is clearly not borne out in the vertical velocity profile, Fig. 14b.

\section{A two-scale model for the Madden-Julian oscillation}

The examples of the previous two sections indicate that the planetary circulation associated with the congestus/supercluster models, $\mathrm{C} / \mathrm{SC}$ and $\mathrm{C} / \mathrm{SCMH}$, have several features in common with observations. Recall that the $\mathrm{C} / \mathrm{SC}$ model discussed in section 4 provides the eddy fluxes from synoptic-scale variations while the $\mathrm{C} / \mathrm{SCMH}$ model in section 5 provides the mean heating consistent with this envelope. The correlation of congestus convection with the onset of a westerly wind burst and tilted convective superclusters with the region of strong westerly burst are also suggested in the reanalysis of observations by Johnson and Lin (1997) and Houze et al. (2000) and this further suggests the use of these models in order to construct a self-consistent MJO model.

Therefore, the MJO model considered here is simply the addition of a moving convective envelope of upscale eddy flux convergence from synoptic-scale heating in the C/SC model from Eq. (4.2), discussed in section 4 , to the $\mathrm{C} / \mathrm{SCMH}$ planetary-scale mean heating 
(a) $0 \mathrm{~km}, U_{\max }=1.3684$

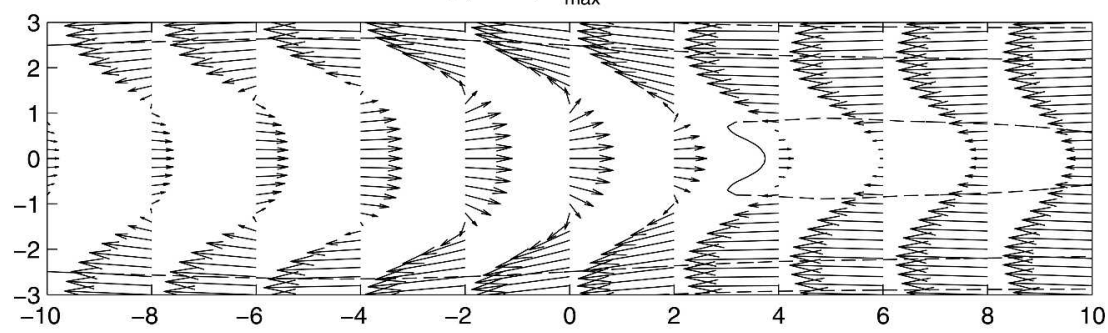

(b) $2 \mathrm{~km}, \mathrm{U}_{\max }=1.6631$

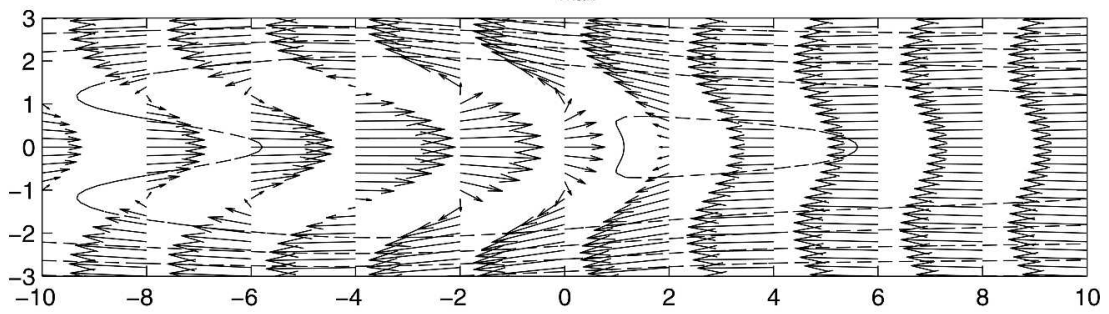

(c) $4 \mathrm{~km}, \mathrm{U}_{\max }=4.1187$

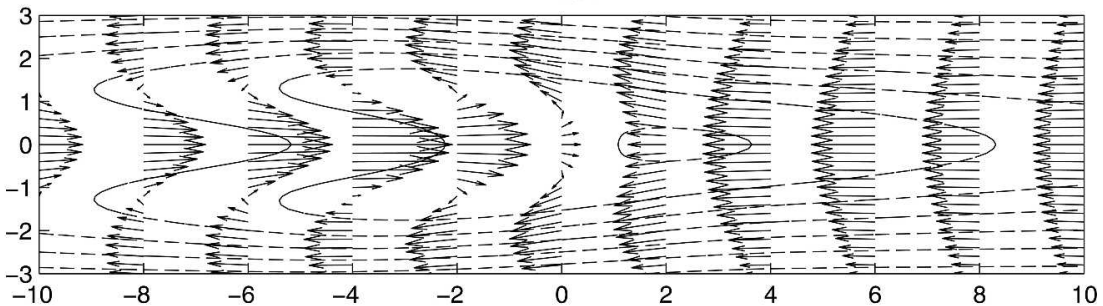

(d) $12 \mathrm{~km}, \mathrm{U}_{\max }=4.1187$

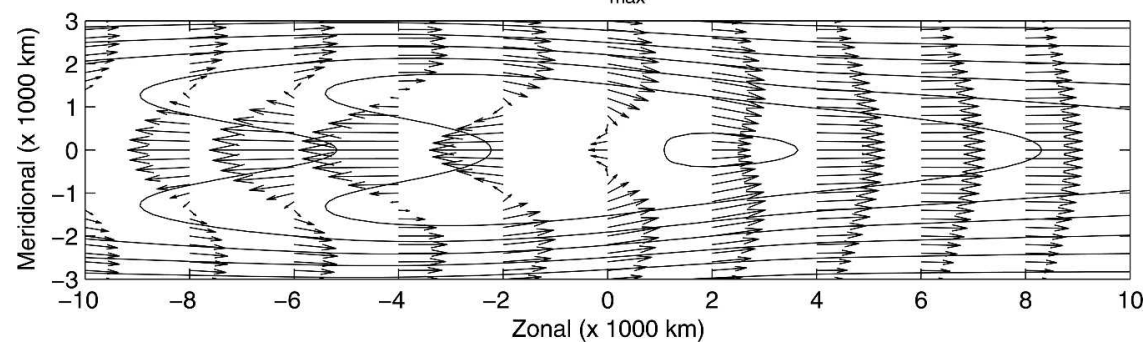

FIG. 11. Same as Fig. 5 for the case of standard mean heating centered at the equator. The maximum velocities at each height are (a) 1.4 , (b) 1.7 , and (c), (d) $4.1 \mathrm{~m} \mathrm{~s}^{-1}$.

from Eqs. (5.3) and (5.4), considered in section 5. This is a natural superposition since, by design, the $\mathrm{C} / \mathrm{SCMH}$ model uses the planetary-scale mean heating associated with the synoptic-scale heating of the C/SC. Through the IPESD models, this combination is truly multiple scale (in fact, two-scale) since it involves balanced equatorial synoptic-scale effects from Eq. (2.5) plus the forcing of planetary scales by the synoptic-scale flux convergences in Eq. (2.7) and planetary-scale direct heating, $\overline{S^{\theta}}$. Since the equatorial long wave Eqs. (2.6) are linear in these two forcings, their solutions are simply a linear superposition of the solutions from C/SC and $\mathrm{C} / \mathrm{SCMH}$. In addition to equatorial symmetric heating, an example of an off-equatorial MJO is given using a moving convective envelope in the $\mathrm{C} / \mathrm{SC}$ plus C/SCMH with a meridional heating profile centered at $450 \mathrm{~km}$ south of the equator.

Lin and Johnson (1996, their Fig. 3) and Yanai et al. (2000, their Fig. 2) clearly capture the vertical structure of the zonal winds in a westerly wind burst that occurred during the TOGA COARE intense observing period (IOP). Hendon and Salby (1994, their Fig. 3) and Hendon and Liebmann (1994, their Fig. 2) construct a composite life cycle of an MJO that captures the horizontal flow structure and pressure profile throughout the Tropics. To compare with the results predicted by the new MJO models, it is useful to summarize these observations. 
(a)

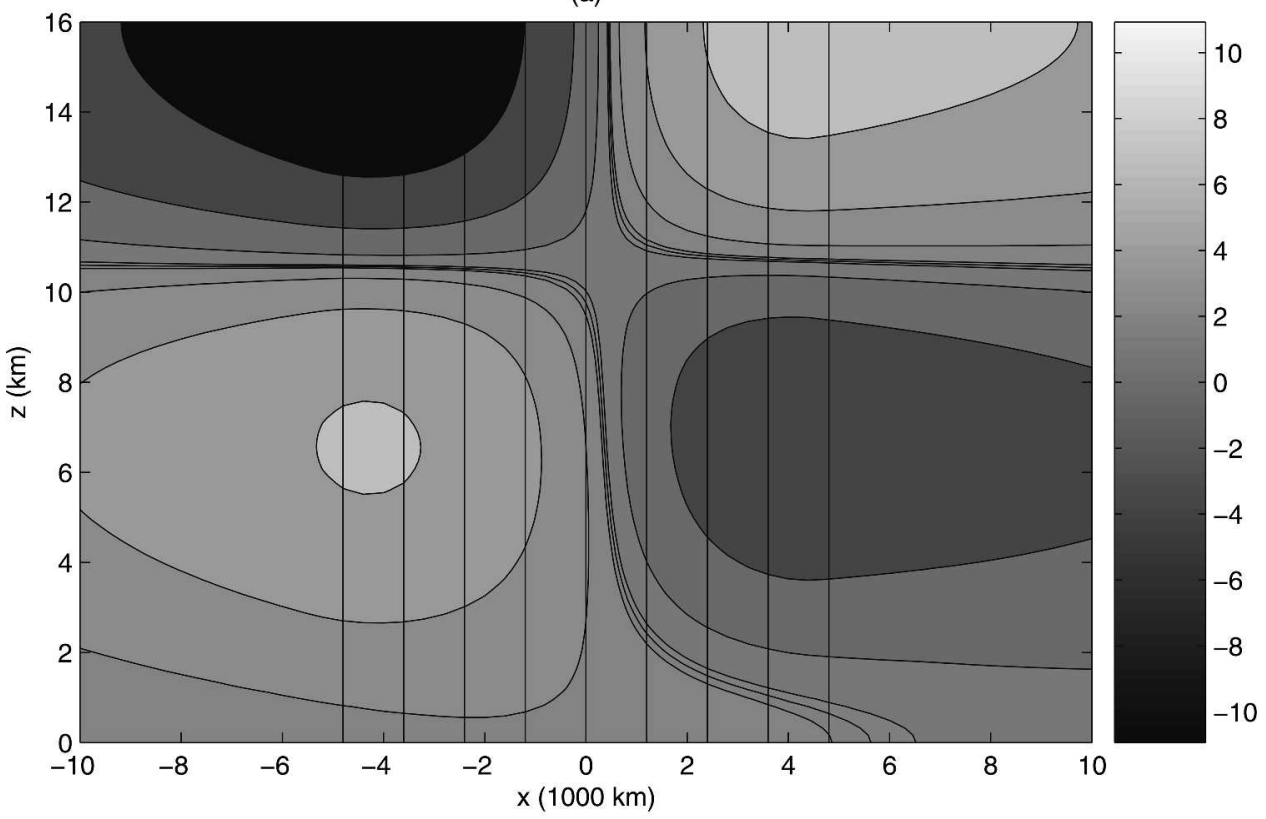

(b)

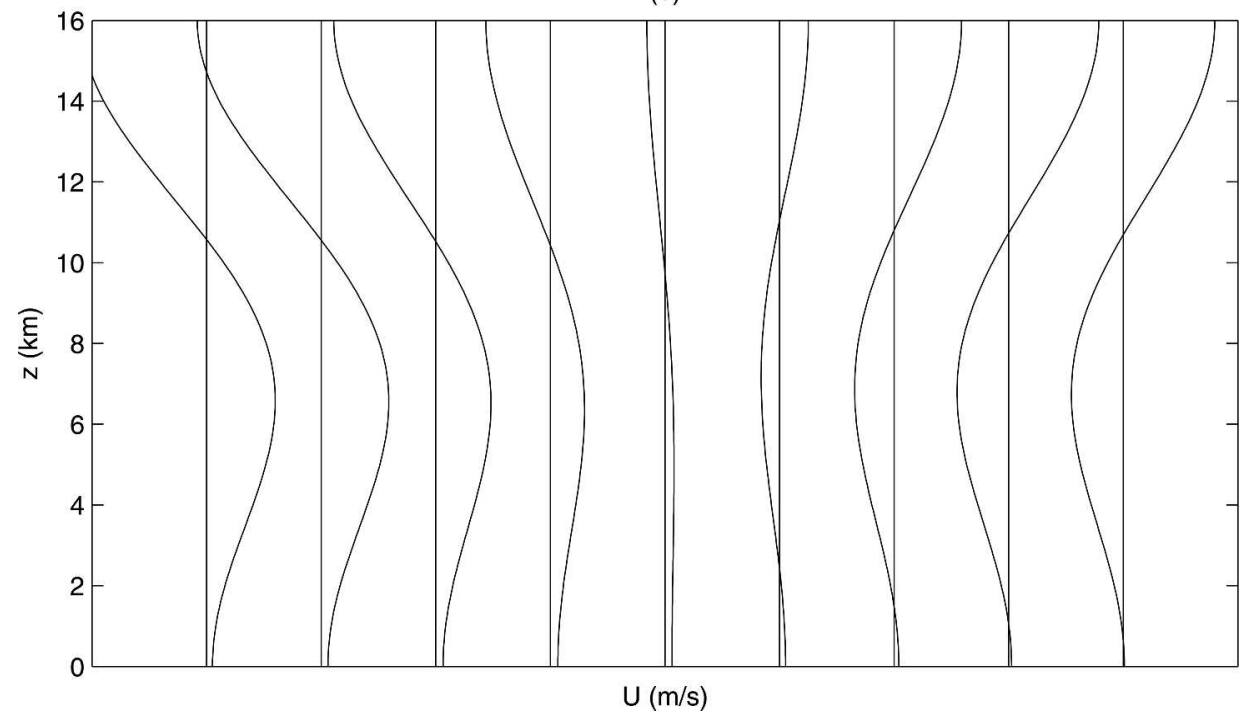

FIG. 12. Same as Fig. 6 for the case of standard mean heating centered at the equator.

1) Easterly winds precede westerlies as the westerly wind burst moves from east to west at roughly 5 $\mathrm{m} \mathrm{s}^{-1}$.

2) In the lower troposphere, the maximum westerly winds occur at heights of 4-6 km and are larger than those at the base of the troposphere.

3) The westerly wind burst has a distinct upward/ westward tilt so that in the onset region the westerlies first appear at the base of the troposphere and then encroach upward. It took about 15 days (about $6500 \mathrm{~km}$ in distance assuming a steady wave passing at $5 \mathrm{~m} \mathrm{~s}^{-1}$ ) from the time that the IOP westerly wind burst set in at the base of the troposphere for it to reach its maximum at about $4 \mathrm{~km}$ (Lin and Johnson 1996; Yanai et al. 2000).

4) The IOP data shows a very strong easterly wind in the upper troposphere coincident with the westerly wind burst in the lower troposphere while a clear upper troposphere westerly overlies the easterlies which precede the westerly wind burst (Lin and Johnson 1996; Yanai et al. 2000). This is also manifested as an outflow from the convective envelope in the upper troposphere (Hendon and Liebmann 1994). 


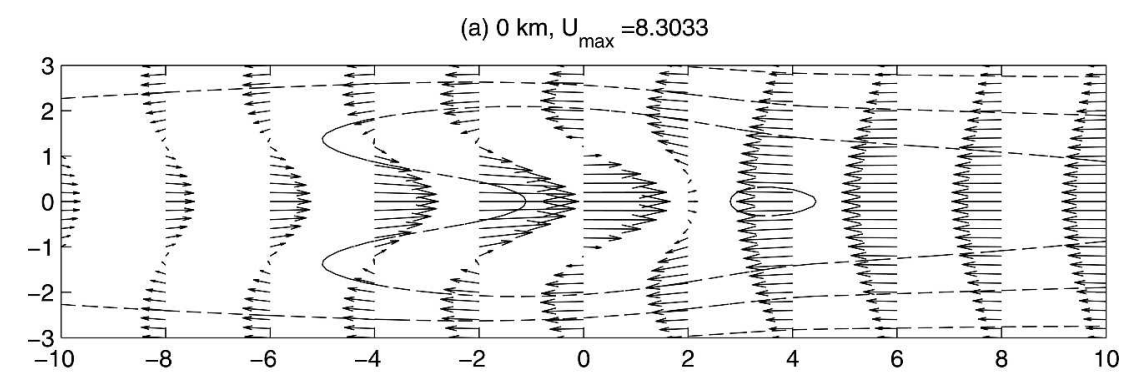

(b) $2 \mathrm{~km}, \mathrm{U}_{\max }=6.6549$

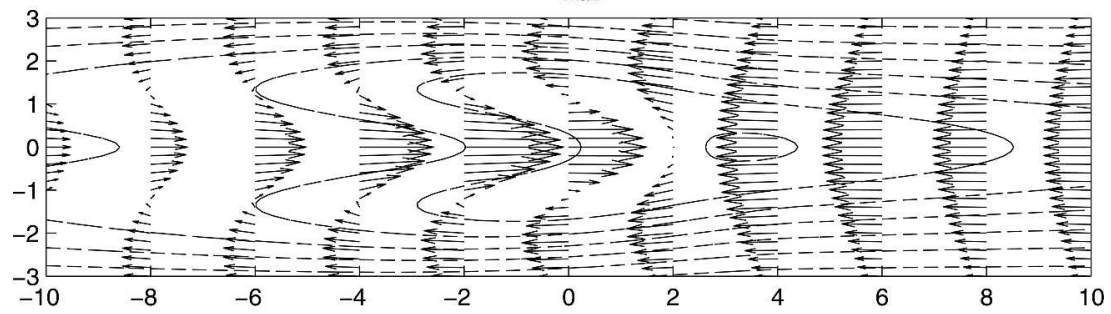

(c) $4 \mathrm{~km}, \mathrm{U}_{\max }=4.1187$

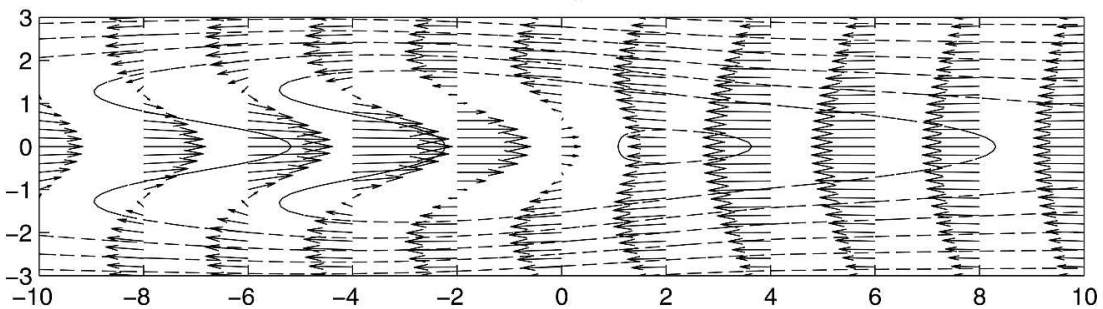

(d) $12 \mathrm{~km}, \mathrm{U}_{\max }=4.1187$

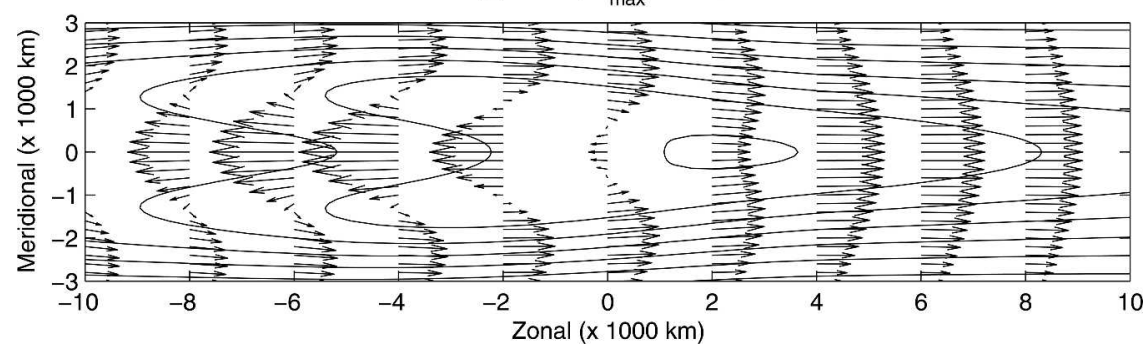

FIG. 13. Same as Fig. 5 for the case of congestus/supercluster mean heating centered at the equator. The maximum velocities at each height are (a) 8.3 , (b) 6.7 , and (c), (d) $4.1 \mathrm{~m} \mathrm{~s}^{-1}$.

5) The planetary-scale filtered MJO envelope has a distinctive quadrupole flow structure. In the lower troposphere, there is a symmetric leading pair of off-equatorial anticyclones extending to roughly $\pm 2500 \mathrm{~km}$ north and south of the equator with leading low-level easterly flow while the trailing flow is a cyclone pair extending to $\pm 2500 \mathrm{~km}$ north and south with a strong "westerly wind burst" region of flow on the equator. (Hendon and Liebmann 1994, their Fig. 2; Hendon and Salby 1994, their Fig. 3; Maloney and Hartmann 1998, their Figs. 7 and 9).

The planetary-scale flow for the equatorially symmetric heating MJO model is shown in Figs. 15 and 16 and the agreement of its features with those in the observational record listed above is striking. As in the preceding section, the $5 \mathrm{~m} \mathrm{~s}^{-1}$ MJO speed is built into the model through the moving convective envelope. Throughout the lower half of the troposphere, easterlies precede westerlies and this situation is reversed in the upper half of the troposphere. There is a pronounced upward/westward tilt in the westerly wind burst evident in Fig. 16a from the base to the middle of the troposphere. From Fig. 16b it is clear that the maximum westerly winds occur at heights of 4 to $6 \mathrm{~km}$ in the western side of the moving envelope, below which the westerlies are weaker. The wind burst width is not clearly defined, however from Fig. 15a, an inferred 
(a)

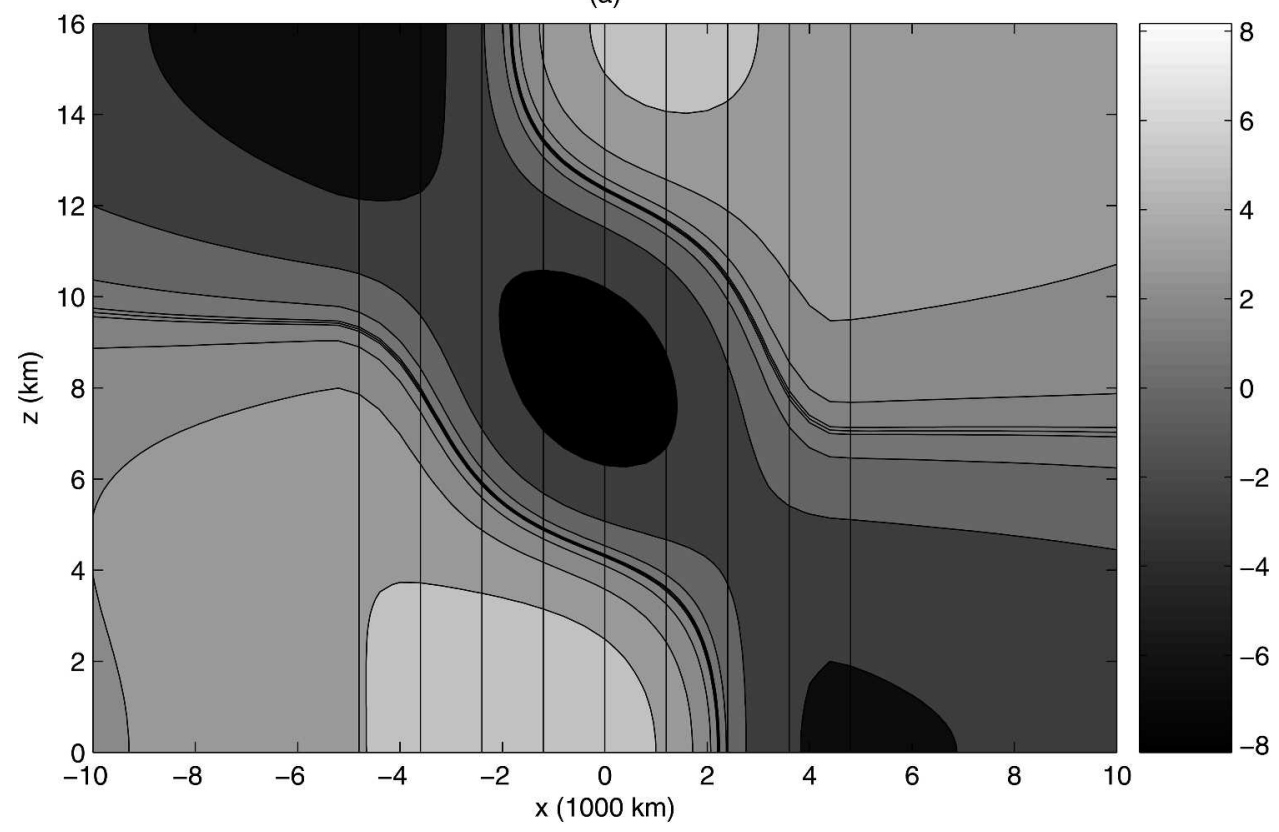

(b)

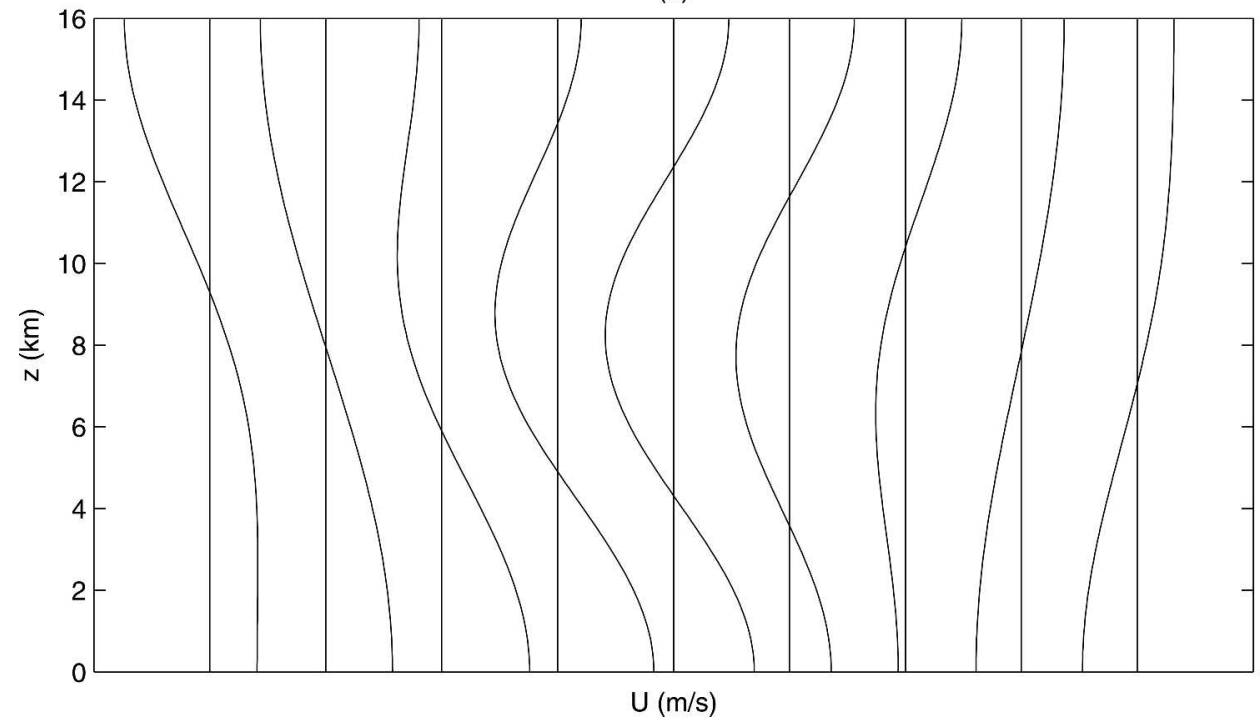

FIG. 14. Same as Fig. 6 for the case of congestus/supercluster mean heating centered at the equator.

width at the base of the troposphere is about $8000 \mathrm{~km}$. In particular, Fig. 16 compares very favorably with Lin and Johnson (1996, their Fig. 3) and Yanai et al. (2000, their Fig. 2).

A pair of anticyclones centered over the convective envelope extending to about $2000 \mathrm{~km}$ north and south clearly precedes a pair of cyclones at the back of the convective envelope in Figs. 15c,d. Coincident with this quadrupole is an outflow from the convective region at heights of $12 \mathrm{~km}$, which is manifested in Fig. 16a as westerlies preceding easterlies at that height. This quadrupole is very similar to that shown in Hendon and Salby (1994, their Fig. 3).
The results for off-equatorial heating, shown in Figs. 17 and 18, should reflect an individual MJO event (rather than a statistical composite MJO) occurring in the austral summer, as was observed during the TOGA COARE IOP. The vertical profile of the zonal flow shown in Fig. 18 is qualitatively exactly the same as that of the equatorial symmetric case in the MJO model: the upward/westward tilt, the upper troposphere outflow, and the height of the maximum zonal velocity are unchanged. As in the off-equatorial C/SC examples, the horizontal profile of the pressure and flow do acquire a strong asymmetry in this example. The most significant difference lies in the asymmetry of the quadrupoles 


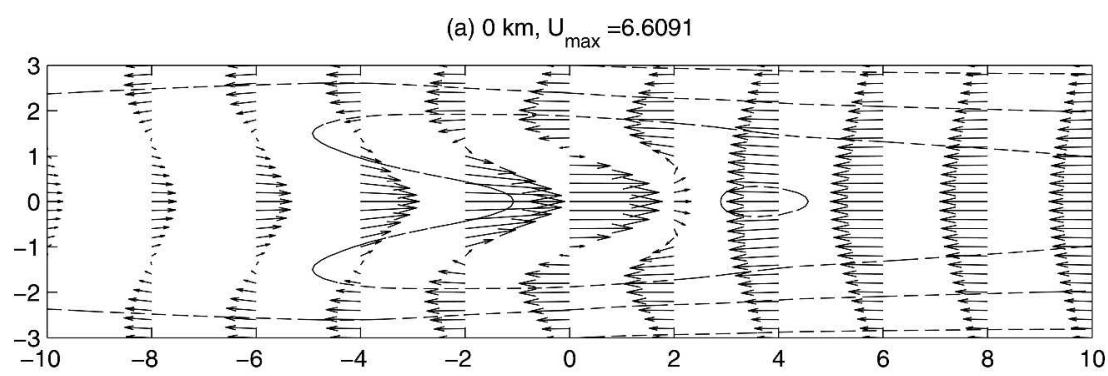

(b) $2 \mathrm{~km}, \mathrm{U}_{\max }=4.9154$

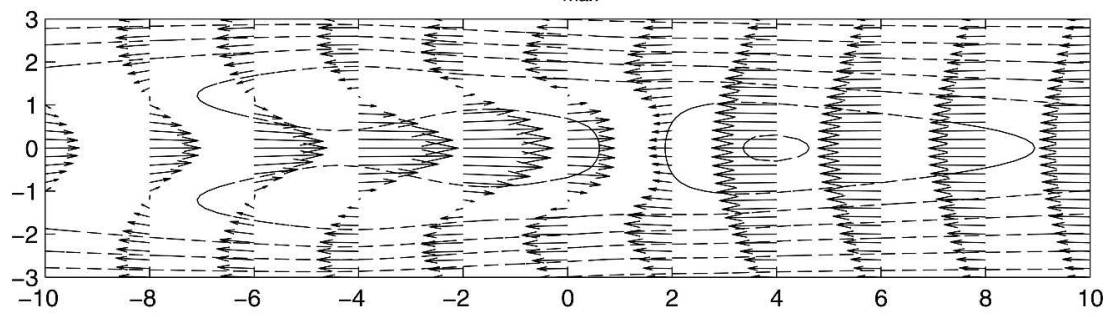

(c) $4 \mathrm{~km}, \mathrm{U}_{\max }=6.7299$

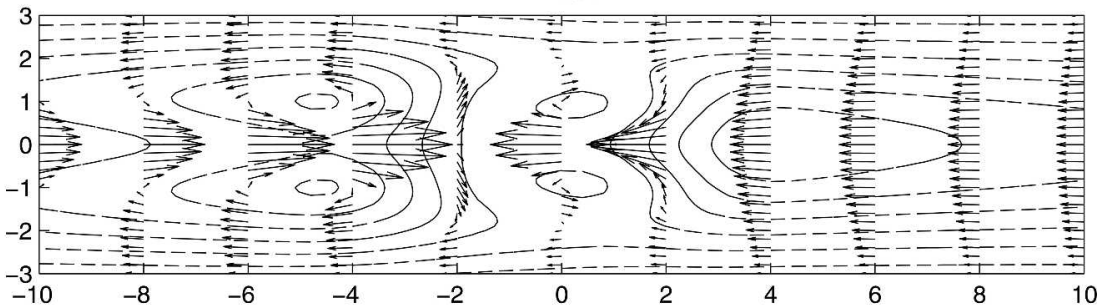

(d) $12 \mathrm{~km}, \mathrm{U}_{\max }=6.7298$

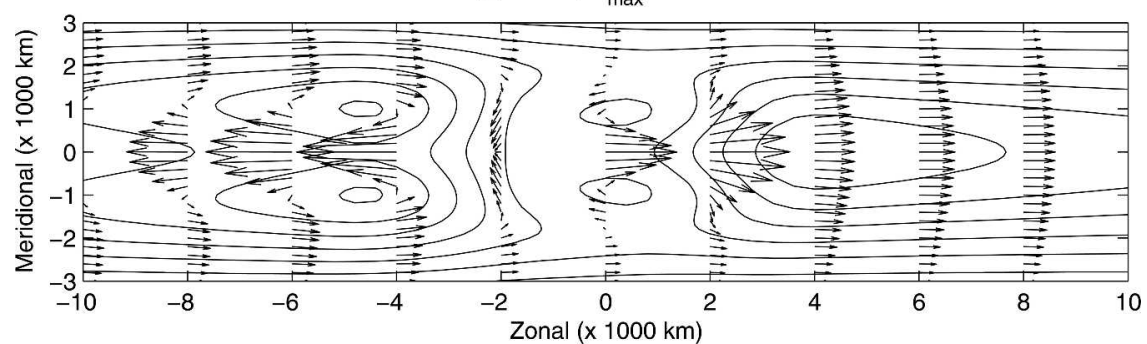

FIG. 15. Same as Fig. 5 for the case of congestus/supercluster synoptic and mean heating centered at the equator-the MJO model. The maximum velocities at each height are (a) 6.6, (b) 4.9 , and (c), (d) $6.7 \mathrm{~m} \mathrm{~s}^{-1}$. The deep convection is located in $x=[-5000,0] \mathrm{km}$ and reaches a maximum at about $x=-2500 \mathrm{~km}$.

whose northern gyres are weakened in comparison to the previous example; however, there remains a weak anticyclonic/cyclonic pair of gyres. The center outflow jets in the upper troposphere move southward only slightly in this example and at all heights the wind is strengthened. This horizontal structure strongly resembles that from the MJO in the TOGA COARE IOP (Yanai et al. 2000).

\section{Concluding discussion}

A new multiscale model for the planetary-scale circulation during an MJO has been systematically de- rived from a two-scale model of heating in a moving convective envelope using the IPESD equations derived by Majda and Klein (2003) for the interaction of equatorial synoptic and planetary-scale flows. The appeal of the present theory is its firm mathematical underpinnings, simplicity, and analytic tractability while remaining self-consistent with many features of the observational record for tropical intraseasonal variability. While the theory is nonlinear, it is actually "quasilinear" and is analyzed by exactly solving linear problems in two stages. First, the synoptic-scale heating fluctuations drive synoptic-scale flows within a moving convective envelope through balanced dynamics, which 
(a)

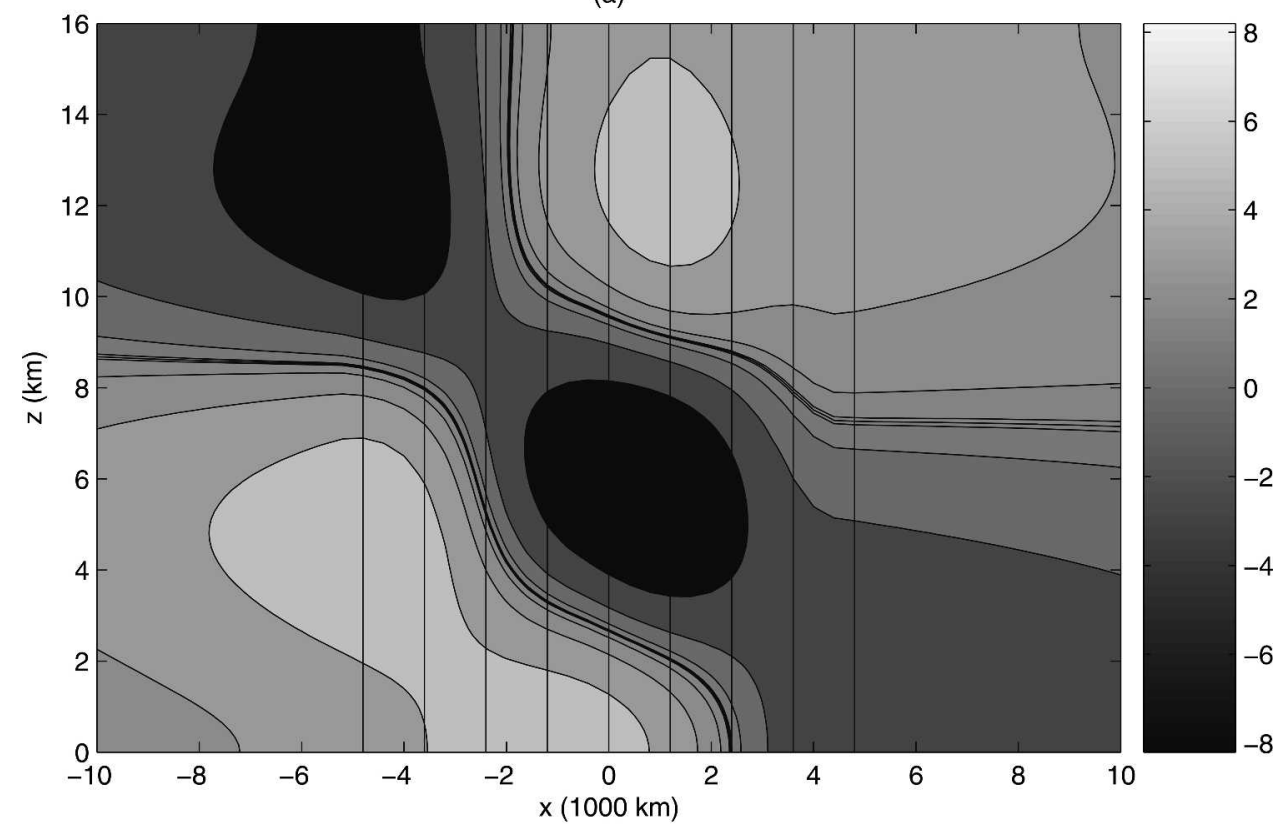

(b)

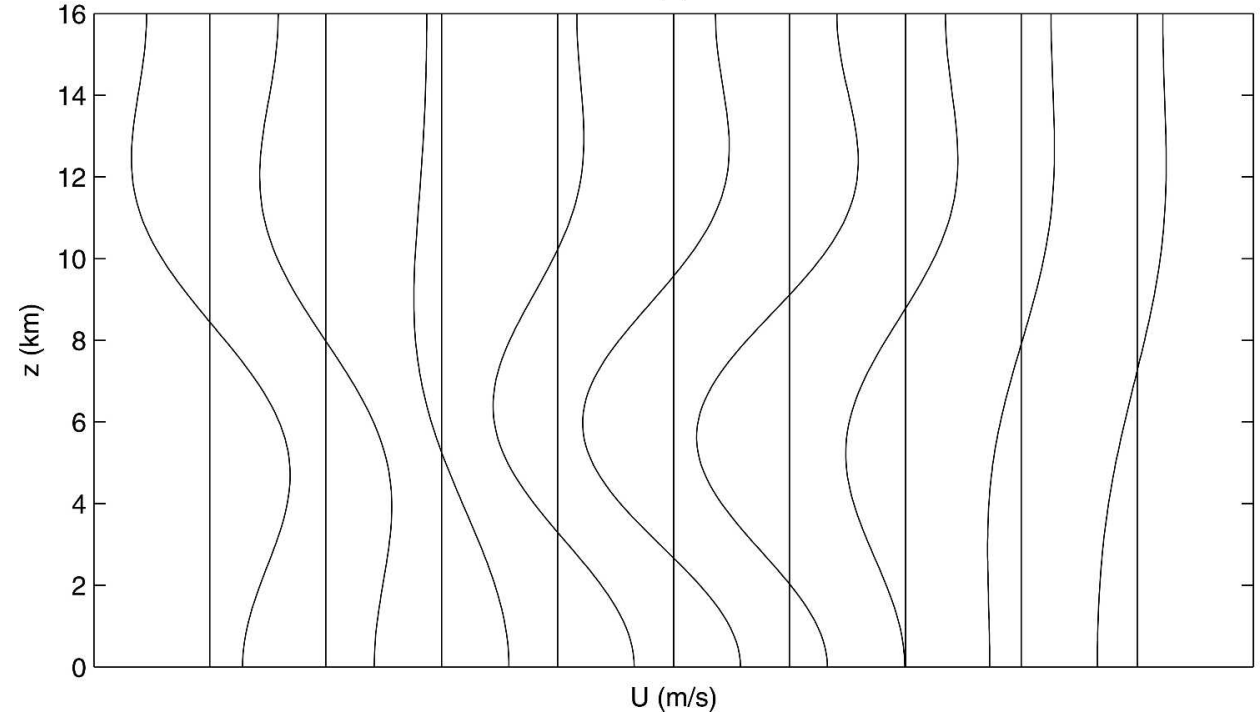

FIG. 16. Same as Fig. 6 for the case of congestus/supercluster synoptic and mean heating centered at the equator-the MJO model. The deep convection is located in $x=[-5000,0] \mathrm{km}$ and reaches a maximum at about $x=-2500 \mathrm{~km}$.

drive upscale fluxes of heat and zonal momentum. The multiscale IPESD model provides a rigorous asymptotic closure for zonal momentum and thermal fluxes on the planetary-scale, which are calculated explicitly from the synoptic-scale fluctuations. In the balance dynamics, the zonal momentum flux dominates the temperature flux whenever the synoptic-scale heating is centered about the equator.

In the second stage, the planetary response is computed by solving the linear equatorial long wave equa- tions with a known planetary-scale mean heating plus forcing arising from the convergence of the mean upscale fluxes of heat and zonal momentum from the synoptic scales. Those equations resemble superficially those of Chao (1987) in the linear moving heat source model of the MJO that is based on the Gill model (Gill 1980) for circulations induced by heating; however the interpretation and derivation is completely different here for, in addition to planetary-scale thermal forcing, there is both planetary-scale momentum forcing, $F^{U}$, 
(a) $0 \mathrm{~km}, U_{\text {max }}=9.2627$

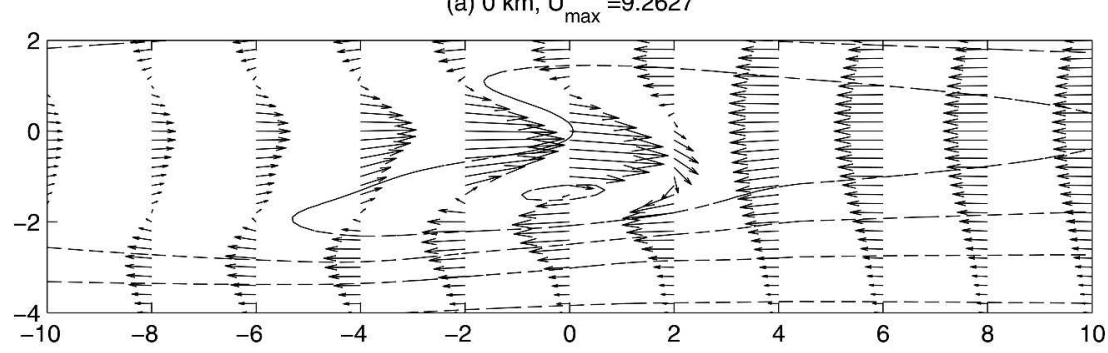

(b) $2 \mathrm{~km}, U_{\max }=6.242$

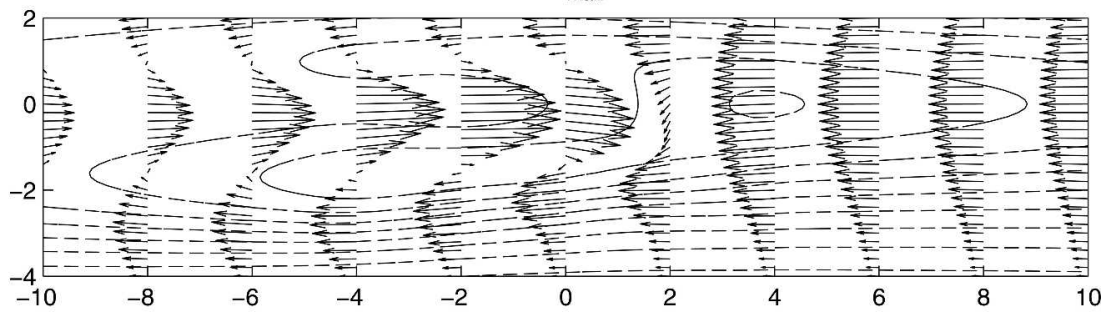

(c) $4 \mathrm{~km}, \mathrm{U}_{\max }=7.2477$

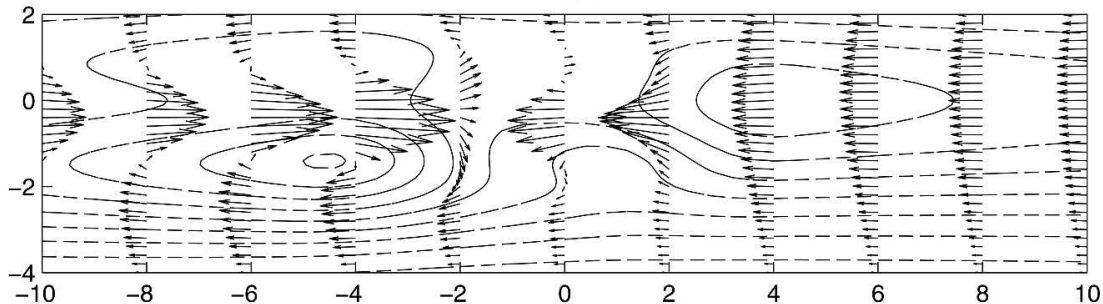

(d) $12 \mathrm{~km}, \mathrm{U}_{\max }=7.2477$

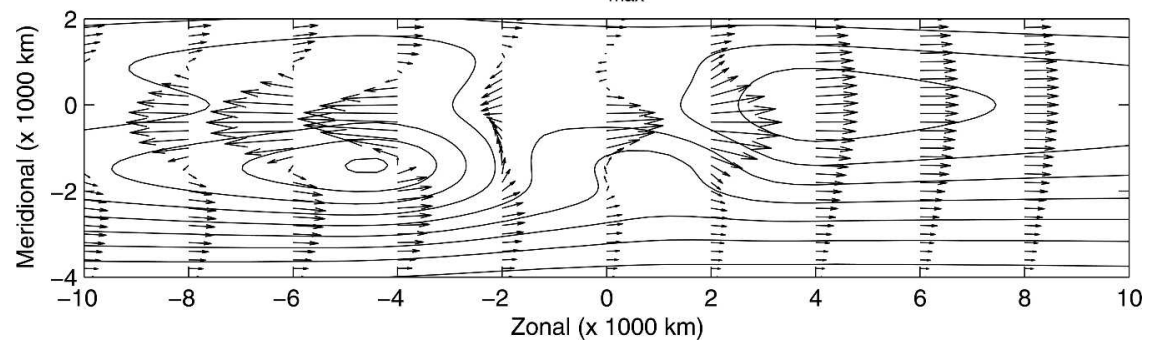

FIG. 17. Same as Fig. 5 for the case of congestus/supercluster synoptic and mean heating centered at $450 \mathrm{~km}$ south - the off-equatorial MJO model. The maximum velocities at each height are (a) 8.8, (b) 5.6, and (c), (d) $7.6 \mathrm{~m} \mathrm{~s}^{-1}$. The deep convection is located in $x=[-5000$, $0] \mathrm{km}$ and reaches a maximum at about $x=-2500 \mathrm{~km}$.

and thermal forcing, $F^{\theta}$, generated through derived synoptic-scale fluxes with momentum forcing dominating the upscale response. Furthermore, in this paper the profile of the mean heating itself is novel and designed to be self-consistent with the profiles of the synopticscale structures.

The genuine multiscale models for the MJO developed here share a common theme with Moncrieff's (2004) interesting recent phenomenological theory for the upscale transport of momentum from equatorial mesoscales $O(300 \mathrm{~km})$ to planetary scales, which is based on an ad hoc closure principle. In detail, the two approaches are quite different with the present models focusing on the transfer of kinetic and thermal energy from equatorial synoptic scales to planetary scales with a systematic derived closure principle for the large scale envelope with planetary responses allowing for equatorial Kelvin waves (Majda 2003) as in the low-level easterly flow in Fig. 15 and Rossby waves.

Recent observational results have identified a regime of congestus convective heating leading westward tilted superclusters in the moving envelope of the MJO (Johnson and Lin 1997; Houze et al. 2000; Kiladis et al. 2005); congestus heating is identified with the "westerly 
(a)

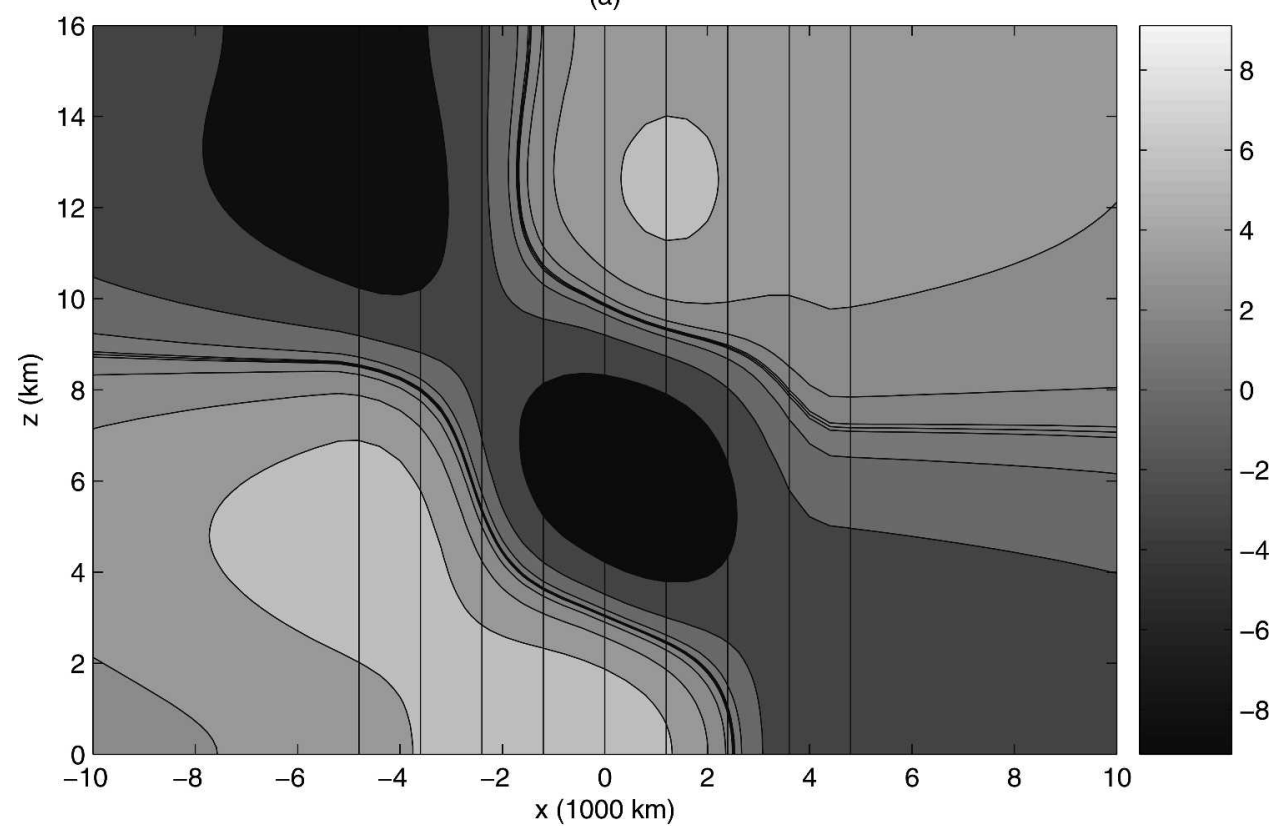

(b)

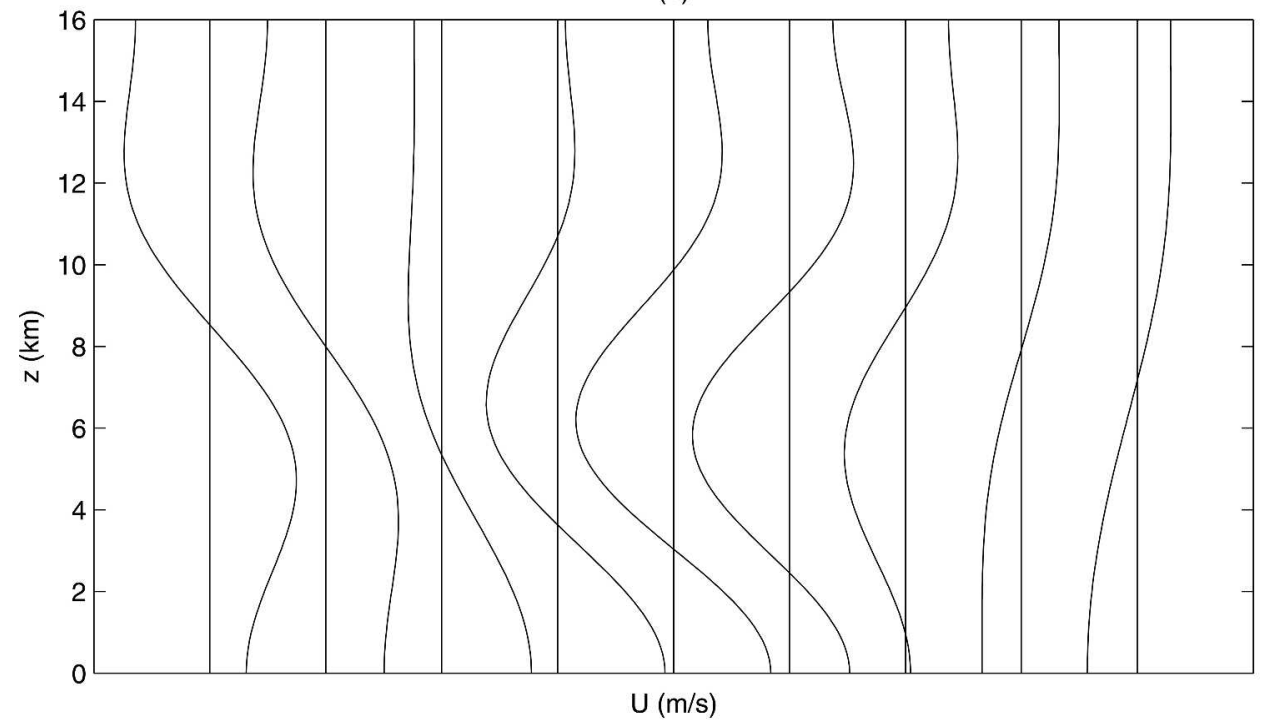

FIG. 18. Same as Fig. 6 for the case of congestus/supercluster synoptic and mean heating centered at $450 \mathrm{~km}$ south - the off-equatorial MJO model. The deep convection is located in $x=[-5000,0] \mathrm{km}$ and reaches a maximum at about $x=-2500 \mathrm{~km}$.

onset region" and superclusters with the "strong westerly region" of the MJO. The MJO model developed here uses this intuition to drive the fluctuating heating on synoptic scales (westward-tilted superclusters to the west and lower troposphere congestus heating to the east) with a self-consistent envelope of planetary-scale heating (upper-troposphere heating maximum to the west, lower-troposphere maximum to the east) within a moving convective envelope. The primary planetary ef- fect of westward-tilted superclusters is to drive westerly momentum downward in the troposphere while congestus heating drives easterly momentum downward; the upscale temperature fluxes are of much smaller magnitude. As regards the planetary-scale heating, an uppertroposphere maximum drives weaker convergent winds at the base of the troposphere than does a lower-troposphere maximum.

The planetary-scale flow in the MJO model devel- 
oped here agrees extremely well qualitatively with the observations. The main effects captured by this model are the westerlies trailing easterlies in the lower troposphere, the upward/westward tilt of the westerly wind burst, the wind burst maximum above the base of the troposphere, the upper troposphere outflow from the convective envelope and the horizontal quadrupolar anticyclonic/cyclonic circulation pattern within the envelope of convective activity. Additionally, the model begins by assuming that congestus heating leads convective superclusters; in the resultant planetary response computed in the model the Rossby gyres are correlated with the superclusters while the low-level easterlies overlie the congestus heating region as in the observations (Johnson and Lin 1997; Houze et al. 2000). Furthermore, as shown above in Figs. 7 and 8 of section 4, the upscale eddy flux divergences from the synoptic-scale fluctuations are responsible for the horizontal quadrupole vortex structure, the intense midlevel westerly jet in the strong westerly wind burst region and the intensification of the midlevel easterly jet in the westerly onset region.

\section{The role of active convection}

While the present model does not have an active parameterization for convection, it is broadly selfconsistent with the current picture of the region of deep convection in the MJO as occurring between the westerly onset region and the strong westerly wind burst regions (Lin and Johnson 1996, their Fig. 16; Zhang and Anderson 2003). Here the strong vertical shear in the midlevel westerly jet in the strong westerly region clearly is a mechanism that inhibits deep penetrative convection and can shut down convection in the MJO; recall from (3.6) that this jet is produced from upscale eddy momentum fluxes involving the third baroclinic mode. Similarly, the strong midlevel easterly jet leading the westerly jet region has enough vertical shear to inhibit deep convection in the easterly region but allows for crucial lower troposphere moistening through congestus wave trains as a precondition for the trailing deep convective envelope. Both of these processes are important for the potential capability of GCMs in capturing the MJO (Inness et al. 2001; Slingo et al. 2003). Furthermore, the midlevel off-equatorial horizontal anticyclone pair leading the westerly onset region generated by upscale fluxes with its corresponding midlevel descending air helps to focus the packets of congestus convection leading the MJO toward the equator. Thus, the present MJO model provides both several diagnostic and predictive tests for both observations and current GCM simulations of the MJO.

The present model can be elaborated in several ways. It neglects the upscale transport of momentum from mesoscales to planetary scales, which can also be treated in the systematic multiscale framework (Majda and Klein 2003). It does not provide a theory for the MJO phase speed, which must be related to the feed- back of planetary-scale flows on the meso- and synoptic-scale convective organization. Finally, the atmospheric boundary layer is important for feeding convective processes in the troposphere through thermal effects, Ekman pumping, and as a source of momentum drag on the winds. The effect of the boundary layer on all scales of interaction (meso-, synoptic, and planetary) should be included in order to understand its effects in a more comprehensive model of the MJO. The effect of the mechanical boundary layer in the IPESD models as well as various modulations of the present MJO model have been developed recently by the authors (Biello and Majda 2005, manuscript submitted to Dyn. Atmos. Oceans).

Acknowledgments. The authors thank George Kiladis for many helpful discussions about the observational record of the MJO. The research of Andrew Majda is partially supported by a grant from the Office of Naval Research, ONR N00014-96-1-0043 and two National Science Foundation Grants, NSF DMS96225795 and NSF-FRG DMS-0139918. Joseph Biello is supported as a postdoctoral research associate with A. Majda through National Science Foundation Grant NSF-FRG DMS-0139918.

\section{REFERENCES}

Bretherton, C. S., and A. H. Sobel, 2003: The Gill model and the weak temperature gradient approximation. J. Atmos. Sci., 60, 451-460.

Chao, W. C., 1987: On the origin of the tropical intraseasonal oscillation. J. Atmos. Sci., 44, 1940-1949.

Emanuel, K. A., 1987: An air-sea interaction model of intraseasonal oscillations in the Tropics. J. Atmos. Sci., 44, 2324-2340. , and D. J. Raymond, Eds., 1993: The Representation of Cumulus Convection in Numerical Models, Meteor. Monogr., No. 46, Amer. Meteor. Soc., 246 pp.

Gill, A. E., 1980: Some simple solutions for heat induced tropical circulation. Quart. J. Roy. Meteor. Soc., 106, 447-462.

Grabowski, W. W., 2001: Coupling cloud processes with largescale dynamics using the Cloud-Resolving Convection Parameterization (CRCP). J. Atmos. Sci., 58, 978-997.

Haertel, P. T., and G. Kiladis, 2004: On the dynamics of two-day equatorial disturbances. J. Atmos. Sci., 61, 2707-2721.

Hendon, H., and B. Liebmann, 1994: Organization of convection within the Madden-Julian Oscillation. J. Geophys. Res., 99, 8073-8083.

_ , and M. Salby, 1994: The life cycle of the Madden-Julian Oscillation. J. Atmos. Sci., 51, 2225-2237.

Houze, R. A., S. S. Chen, D. E. Kingsmill, Y. Serra, and S. E. Yuter, 2000: Convection over the Pacific warm pool in relation to the atmospheric Kelvin-Rossby wave. J. Atmos. Sci., 57, 3058-3089.

Inness, P. M., J. M. Slingo, S. J. Woolnough, R. B. Neale, and V. D. Pope, 2001: Organization of tropical convection in a GCM with varying vertical resolution: Implications for the simulation of the Madden-Julian Oscillation. Climate Dyn., 17, 777793.

Johnson, R. H., and X. Lin, 1997: Episodic trade wind regimes over the western Pacific warm pool. J. Atmos. Sci., 54, 2020 2034.

Kiladis, G., K. H. Straub, and P. T. Haertl, 2005: Zonal and vertical structure of the Madden-Julian Oscillation. J. Climate, in press. 
Lin, X., and R. H. Johnson, 1996: Kinematic and thermodynamic characteristics of the flow over the western Pacific warm pool during TOGA COARE. J. Atmos. Sci., 53, 695-715.

Ling, J.-L., M. Zhang, and B. Mapes, 2005: Zonal momentum budget of the Madden-Julian Oscillation: The source and strength of equivalent linear damping. J. Atmos. Sci., in press.

Madden, R., and P. Julian, 1972: Description of global scale circulation cells in Tropics with a 40-50 day period. J. Atmos. Sci., 29, 1109-1123.

— , and - 1994: Observations of the 40-50 day tropical oscillation-A review. Mon. Wea. Rev., 122, 814-837.

Majda, A. J., 2003: Waves and PDEs for the equatorial atmosphere and ocean. Introduction to PDEs and Waves for the Atmosphere and Ocean, Courant Institute Lecture Series 9, American Mathematical Society, 199-232.

, and M. G. Shefter, 2001: Models for stratiform instability and convectively coupled waves. J. Atmos. Sci., 58, 15671584.

— Tropics. J. Atmos. Sci., 60, 393-408.

_ , and J. A. Biello, 2004: A multi-scale model for tropical intraseasonal oscillations. Proc. Natl. Acad. Sci., 101, 47364741.

—- B. Khouider, G. Kiladis, K. Straub, and M. Shefter, 2004: A model for convectively coupled tropical waves: Nonlinearity, rotation, and comparison with observations. J. Atmos. Sci., 61, 2188-2205.

Maloney, E., and D. Hartmann, 1998: Frictional moisture convergence in a composite life cycle of the Madden-Julian oscillation. J. Climate, 11, 2387-2403.

Mapes, B. E., 2000: Convective inhibition, subgrid-scale triggering energy, and stratiform instability in a toy tropical wave model. J. Atmos. Sci., 57, 1515-1535.

- , and R. A. Houze, 1995: Diabatic divergence profiles in western Pacific mesoscale convective systems. J. Atmos. Sci., 52 , 1807-1828

Matsuno, T., 1966: Quasi-geostrophic motions in the equatorial area. J. Meteor. Soc. Japan, 44B, 25-43.

Moncrieff, M., 2004: Analytic representation of the large-scale organization of tropical convection. J. Atmos. Sci., 61, 15211538.

, and E. Klinker, 1997: Organized convective systems in the tropical western Pacific as a process in general circulation models: A TOGA COARE case study. Quart. J. Roy. Meteor. Soc., 123, 805-827.

Nakazawa, T., 1988: Tropical super clusters within intraseasonal variations over the western Pacific. J. Meteor. Soc. Japan, 66, 823-839.

Neelin, J. D., 1989: On the interpretation of the Gill model. $J$. Atmos. Sci., 46, 2466-2468.

- I. M. Held, and K. H. Cook, 1987: Evaporation-wind feedback and low-frequency variability in the tropical atmosphere. J. Atmos. Sci., 44, 2341-2348.

Raymond, D. J., 2001: A new model of the Madden-Julian oscillation. J. Atmos. Sci., 58, 2807-2819.

Salby, M., R. Garcia, and H. Hendon, 1994: Planetary-scale circulations in the presence of climatological and wave-induced heating. J. Atmos. Sci., 51, 2344-2367.

Slingo, J., P. Inness, R. Neale, S. Woolnough, and G.-Y. Yang, 2003: Scale interactions on diurnal to seasonal time scales and their relevance to model systematic errors. Ann. Geophys. Italy, 46, 139-155.

Sperber, K. R., J. M. Slingo, P. K. Inness, and W. K.-M. Lau, 1997: On the maintenance and initiation of the intraseasonal oscillation in the NCEP/NCAR reanalysis and in the GLA and UKMO AMIP simulations. Climate Dyn., 13, 769-795.

Straub, K. H., and G. N. Kiladis, 2003: Interactions between the boreal summer intraseasonal oscillation and higher-frequency tropical wave activity. Mon. Wea. Rev., 131, 945-960.

Vecchi, G. A., and D. E. Harrison, 2000: Tropical Pacific sea surface temperature anomalies, El Nino, and equatorial westerly wind events. J. Climate, 13, 1814-1830.

Wang, B., and H. Rui, 1990: Dynamics of the coupled moist Kelvin-Rossby wave on an equatorial beta-plane. J. Atmos. Sci., 47, 397-413.

Wheeler, M., and G. N. Kiladis, 1999: Convectively coupled equatorial waves: Analysis of clouds and temperature in the wavenumber-frequency domain. J. Atmos. Sci., 56, 374-399.

_,- , and P. J. Webster, 2000: Large scale dynamical fields associated with convectively coupled equatorial waves. $J$. Atmos. Sci., 57, 613-639.

Yanai, M., B. Chen, and W.-W. Tung, 2000: The Madden-Julian oscillation observed during the TOGA COARE IOP: Global view. J. Atmos. Sci., 57, 2374-2396.

Zhang, C., and S. Anderson, 2003: Sensitivity of intraseasonal perturbations in SST to the structure of the MJO. J. Atmos. Sci., 60, 2196-2207. 